\title{
The microscopical appearances of human peripheral arteries during growth and aging
}

\author{
INGLE WRIGHT ${ }^{1}$
}

From the Royal Free Hospital, London

SYNOPSIS Twelve peripheral arteries are described in 59 patients of all ages. Accumulation of ground substance in the media, accompanied by small foci of calcification of the internal elastic lamina, was found in the large leg arteries of young adults, and progressively in a wider series of arteries throughout life. This picture showed no relationship to hypertension, to Mönckeberg's sclerosis, or to the development of atheroma. A notable quantity of ground substance may be a feature of early intimal development, and of a thickened intima in adult life, and probably the major constituent of an organizing thrombus.

Organizing thrombi were apparently incidental findings at several sites even in young adults, and showed no association with the state of the arterial wall beneath the lesion, the wall being in fact normal, though accumulated mucopolysaccharide was always present. Atheroma increases with age, and its focal incidence gives way to confluence in the arteries of the leg. Occlusive peripheral artery atheroma was found only in cases where the cause of death was severe atheroma, e.g., coronary artery disease and abdominal aortic aneurysm, or in myxoedema, in which the incidence of occlusive lesions may differ from that in severe generalized atheroma.

Elastic tissue is described in all coats of the artery wall, with some variants of the common pattern. The musculo-elastic cushion is not seen after adolescence, and it is suggested that the cushion represents the growing point of the artery. Longitudinal muscle bundles are almost confined to the popliteal artery, where they may form an essential buttress for a large branching artery subject to unusual external stresses.

The functions and origin of the ground substance are discussed.

Previous studies on the histological appearances of peripheral arteries were carried out in the early part of this century. All included the radial artery, and usually one of the coronary, mesenteric or cerebral vessels. The present study includes these, and also large and small vessels from the limbs. It was planned in order to elucidate any relationship between pathological changes, at different sites, or at different times.

MATERIALS AND METHODS

Lengths measuring $2 \mathrm{~cm}$. of each of the following 12 arteries were removed during the post-mortem examination of 36 cases of all ages, from newborn to 94 years, dying in hospital: the origin of the right posterior communicating artery in the circle of Willis, the right vertebral artery on entering the skull, the right common carotid artery just below the bifurcation, the right brachial artery

'Present address: Institute of Laryngology and Otology, 330-2 Gray's Inn Road, London, W.C. beneath the bicipital aponeurosis, the right radial artery where it overlies the radius and where the pulse is usually taken, the right palmar digital artery on the medial side of the first phalanx of the index finger, the right renal and superior mesenteric arteries on leaving the aorta, the right femoral artery immediately distal to the inguinal ligament, the right popliteal artery in the fossa, the right anterior tibial artery distal to the intermalleolar ligament on the dorsum of the foot, and the right plantar digital artery on the medial side of the second toe.

A further series was obtained from Professor Camps from 23 necropsies on children and young people; these were limited to the femoral, vertebral, renal, and radial arteries, accompanied by a section from the bifurcation of the aorta. Thus there are at least two sets of arteries of either sex in each decade, with some additional material during childhood.

Fixation was in formol-saline. Transverse and longitudinal sections were prepared from all specimens, stained with haematoxylin and eosin and with Verhoeff-van Gieson. In addition, some sections were stained with 
orcein-van Gieson to determine true elastic: Hale's stain for acid mucopolysaccharides; and Naphthochrome Green B to confirm the presence of calcium. Sudan IV was used on frozen sections to determine the presence of fat on all femoral, vertebral, and radial arteries up to 50 years. Weigert-Gram and Yellowsolve I were used for the detection of fibrin.

\section{HISTOLOGICAL APPEARANCES ${ }^{1}$}

The familiar textbook picture of an artery, with its very deeply folded internal elastic lamina, represents only the neonatal muscular artery with any degree of accuracy (Fig. 1). Rather unexpectedly, the carotid, renal, and superior mesenteric arteries were found not to be muscular in type at all, at the sites chosen in this survey, but elastic or intermediate. The renal and superior mesenteric arteries became muscular in a short distance from the aorta.

The neonatal artery is distinguished by the parallel firm edges of the internal elastic lamina on transverse section, the lamina appearing as a continuous sheet. Beneath this lies the media, composed of circular muscle cells, amongst which occasional fine fibres may be seen, which stain like elastin with Verhoeff's stain. Outside the media there is a compact network,

${ }^{1}$ This section was read at the symposium on cardiovascular pathology at the Zoological Society of London on 29 November 1962. mainly elastin, with some collagen; this is the innero part of the adventitia, the outer part of which is mainly collagen, and much less compact. An excep-s? tion is found in the vessels of the brain where theo adventitia contains no elastin fibres, or very few: The proportions of the elastin and collagen in the adventitia are remarkably constant for any site and are similar in childhood and adult life. Certaim exceptions are described in the section on elastic tissue. Less elastin is found in the adventitia of an artery which contains more in the media. The greatest amount of elastin is found in the adventitia of the largest muscular arteries, such as the femoralo renal, and superior mesenteric arteries.

EARLY DEPARTURES FROM THE NEONATAL PATTERNi Of these the musculo-elastic cushion is the moste striking (Fig. 2). The whole or part of the cushion appears to project into the lumen, though post- mortem contraction adds to this effect. It is composed of a network of elastin in which are found muscles cells and ground substance. Fat is not found. These cushions are almost invariably seen at the branching of arteries of the infant or young child. The internat elastica may run below the cushion or be interruptedo by it (Figs. 2 and 3). The cushion usually represents the sole departure from the infant pattern. In thiso

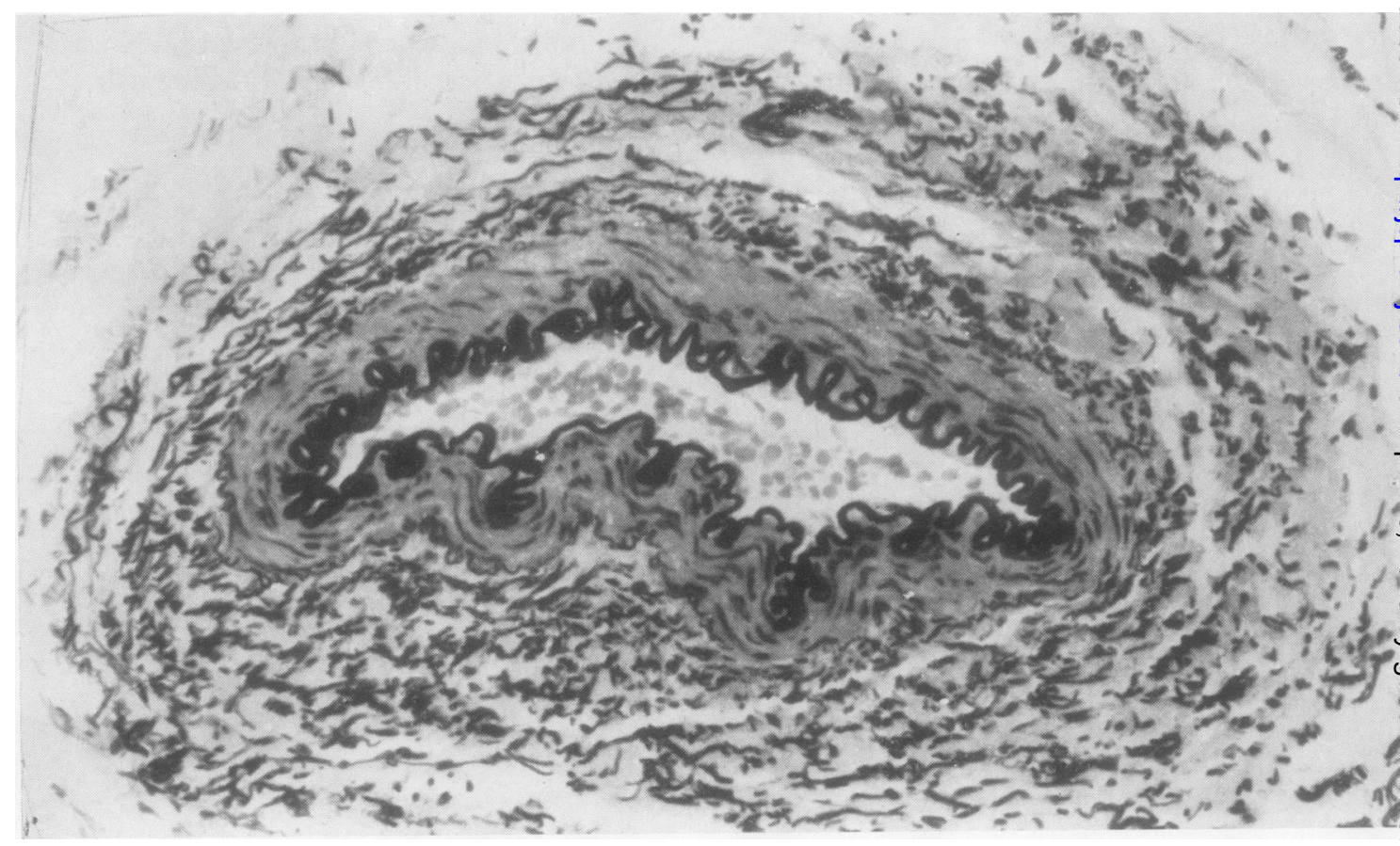

FIG. 1. A typical neonatal artery. Verhoeff-van Gieson $\times 256$. 


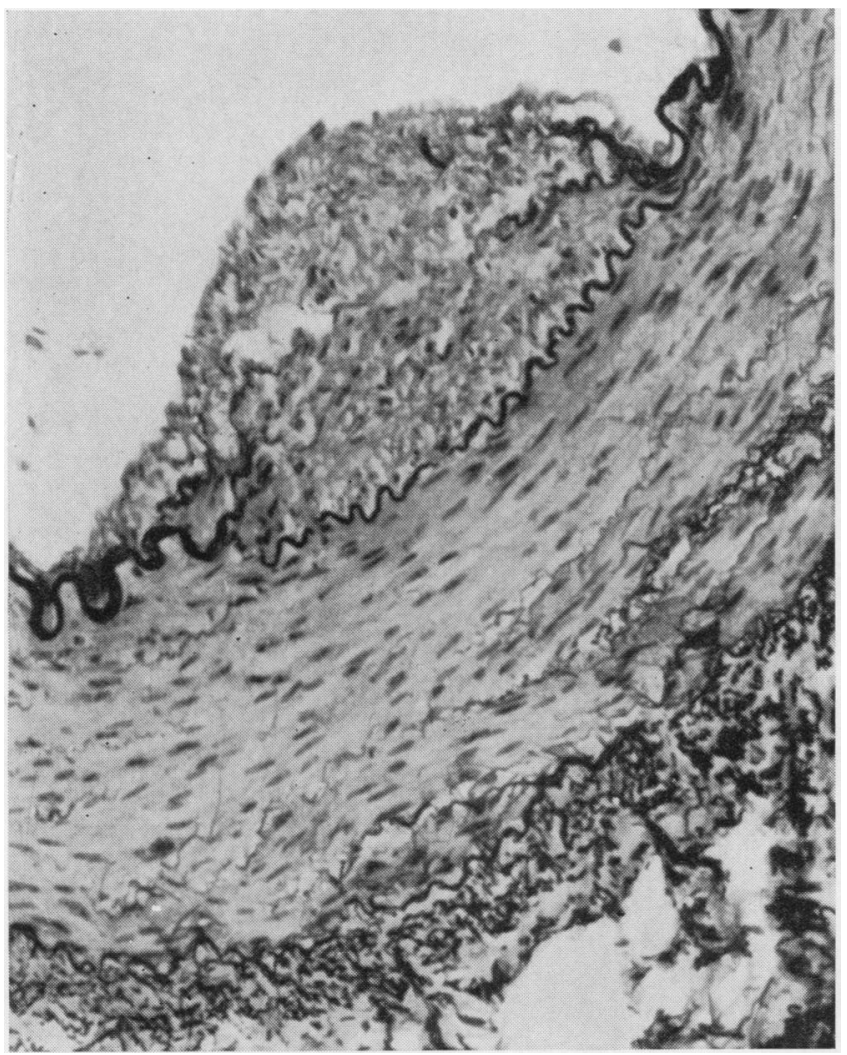

FIG. 2. Musculo-elastic cushion (femoral artery, 4 months). Note relationship of the cushion to the elastic lamina. Verhoeff $\times 160$.

FIG. 3. Musculo-elastic cushions in which a variable relationship is shown to the internal lamina (anterior tibial, 12 years). Verhoeff $\times 160$.

FIG. 2

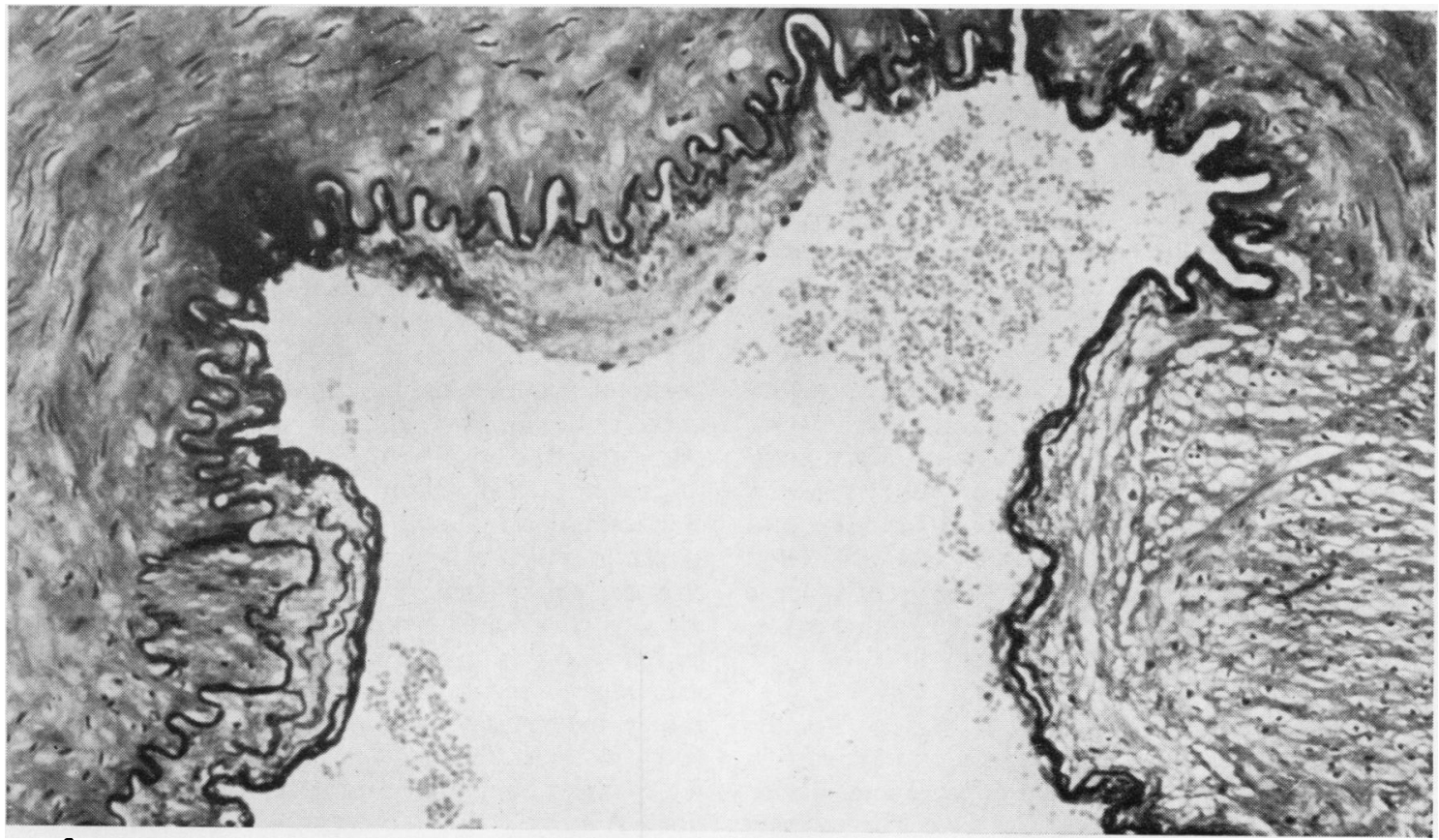

FIG. 3 


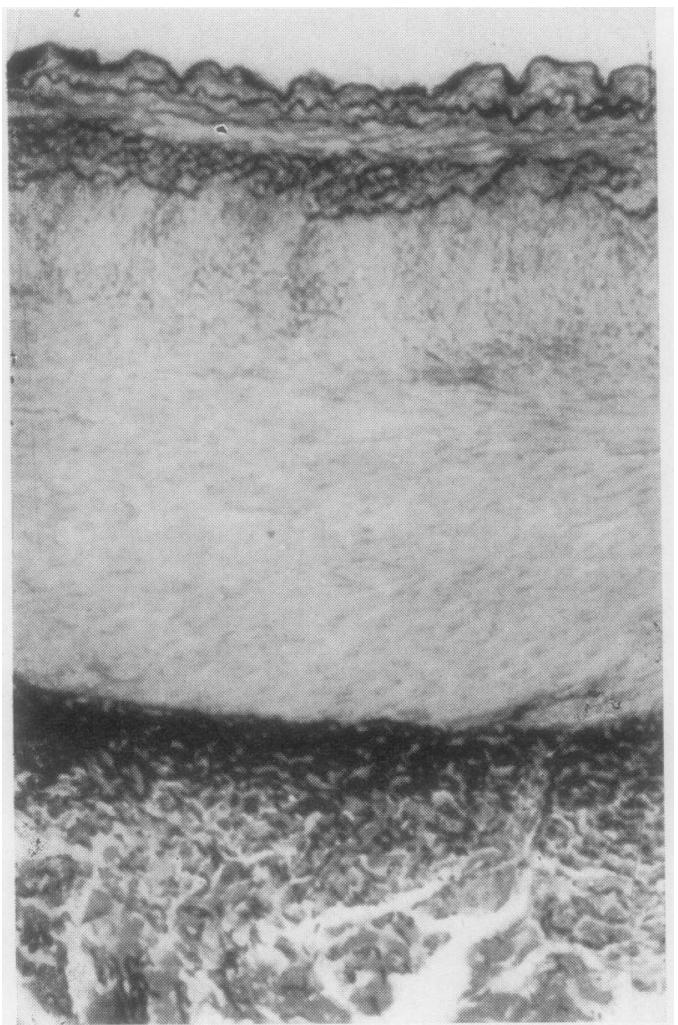

FIG. 4

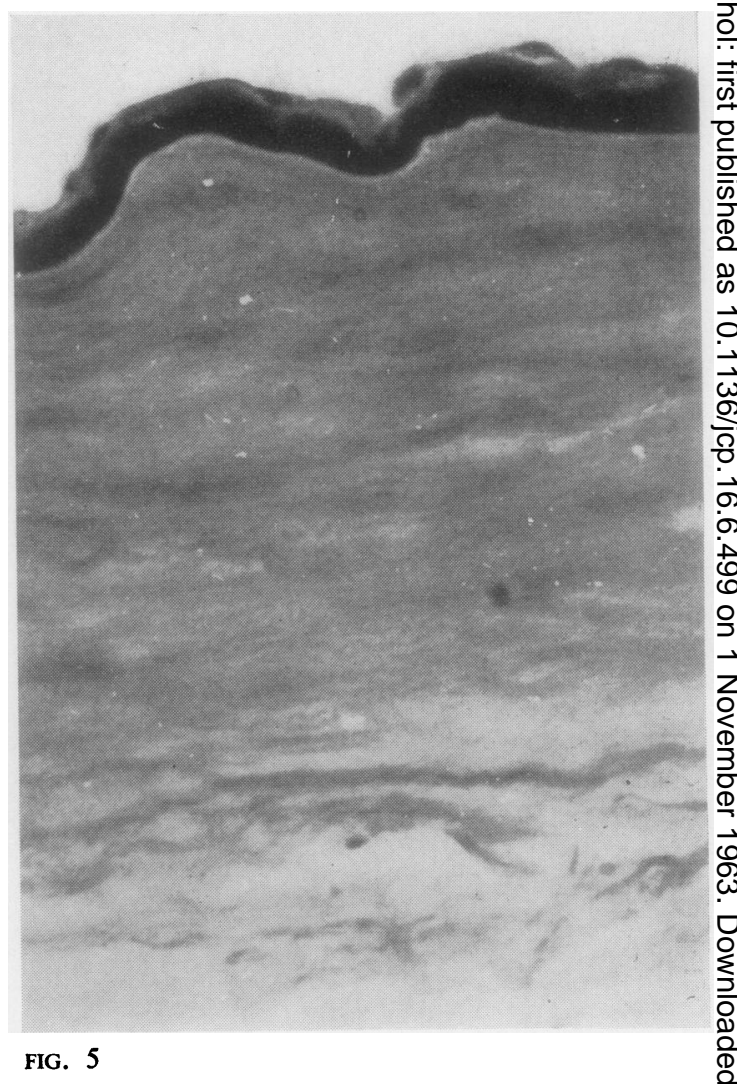

FIG. 5

FIG. 4. Longitudinal muscle bundle between the intima and the circularly arranged muscle of the media (popliteal, 12 years). Verhoeff $\times 40$.

FIG. 5. Swelling and beading of the internal elastic lamina (vertebral, 9 years). Verhoeff $\times 640$.

series it is seen particularly in the femoral and popliteal arteries, from birth onwards. It does not persist into adult life, unlike the longitudinal muscle bundle (Fig. 4), found in every adult popliteal artery, and occasionally elsewhere. The popliteal bundles may be very large, sometimes encircling the whole artery between the internal elastic lamina and the medial circular muscle. In the femoral, brachial, and anterior tibial arteries the bundles may be small, apparently consisting of a few cells only. Some bundles have a very obvious association with branch structure, and occasionally interweaving of differently orientated muscle bundles is seen at the division of a large artery. Where an intact internal elastic lamina exists, the longitudinal bundle lies externally to it.

Other CHANGes OF THE GROWTH PERIOD As the child grows, there is of course a general increase in the size of the vascular tree and appearances suggest an increased number of muscle cells. The internal elastic lamina appears less deeply folded and shows irregularity on the luminal or inner surfaces particus larly, which often gives a beaded, swollen look. This may be seen in many sites in the young child, witle. occasionally a suggestion of separation into tw\& layers. In the adult, the appearance of swelling an $\$$ beading (Fig. 5) is usually seen in the vertebral an $\phi$ posterior communicating arteries only and minor irregularities in the depth of staining with elastie stains may be seen (Fig. 6). There is also a generalize thickening of the intima, usually concentric it character and apparently composed of ground subs stance in which a few connective tissue and muscle्w cells are sometimes visible. Many variable pictures are seen (Fig. 7). Longitudinal fine elastic fibres may be found in this layer (Fig. 8), parallel to each other usually seen end on in transverse section, and thus rather inconspicuous. Layers are sometimes seen between the internal elastic lamina and the lume $\overline{0}$ which are not unlike a compressed series of suci fibres (Fig. 9). A different layer, very like the internat elastic lamina, appears in early childhood on the 


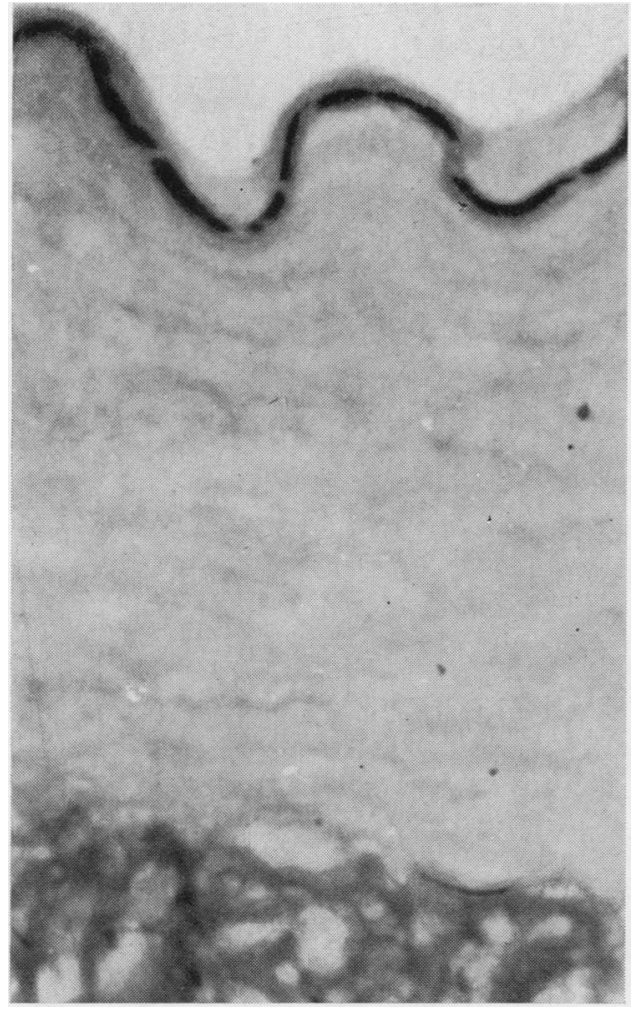

FIG. 6

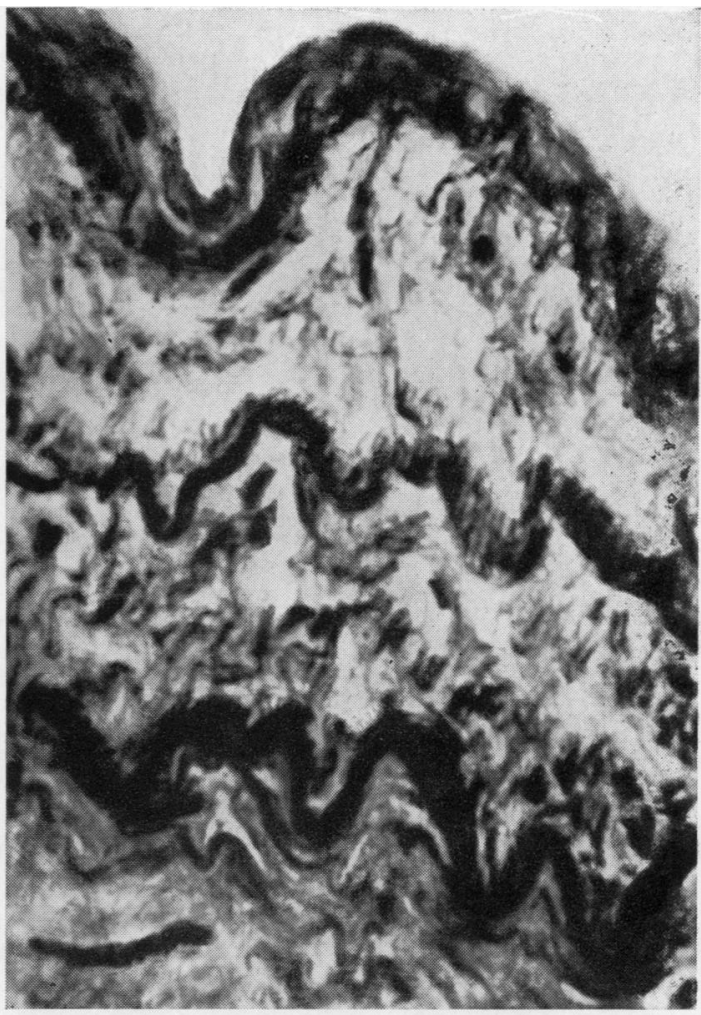

FIG. 8

FIG. 6. Irregular staining of the internal elastic lamina. A thin variable intima is present and occasional endothelial nuclei may be seen (anterior tibial, 2 years). Verhoeff $\times 800$.

FIG. 8. Elastin fibres in the intima: many of these are longitudinally arranged (popliteal, 12 years). Verhoeff $\times 640$.
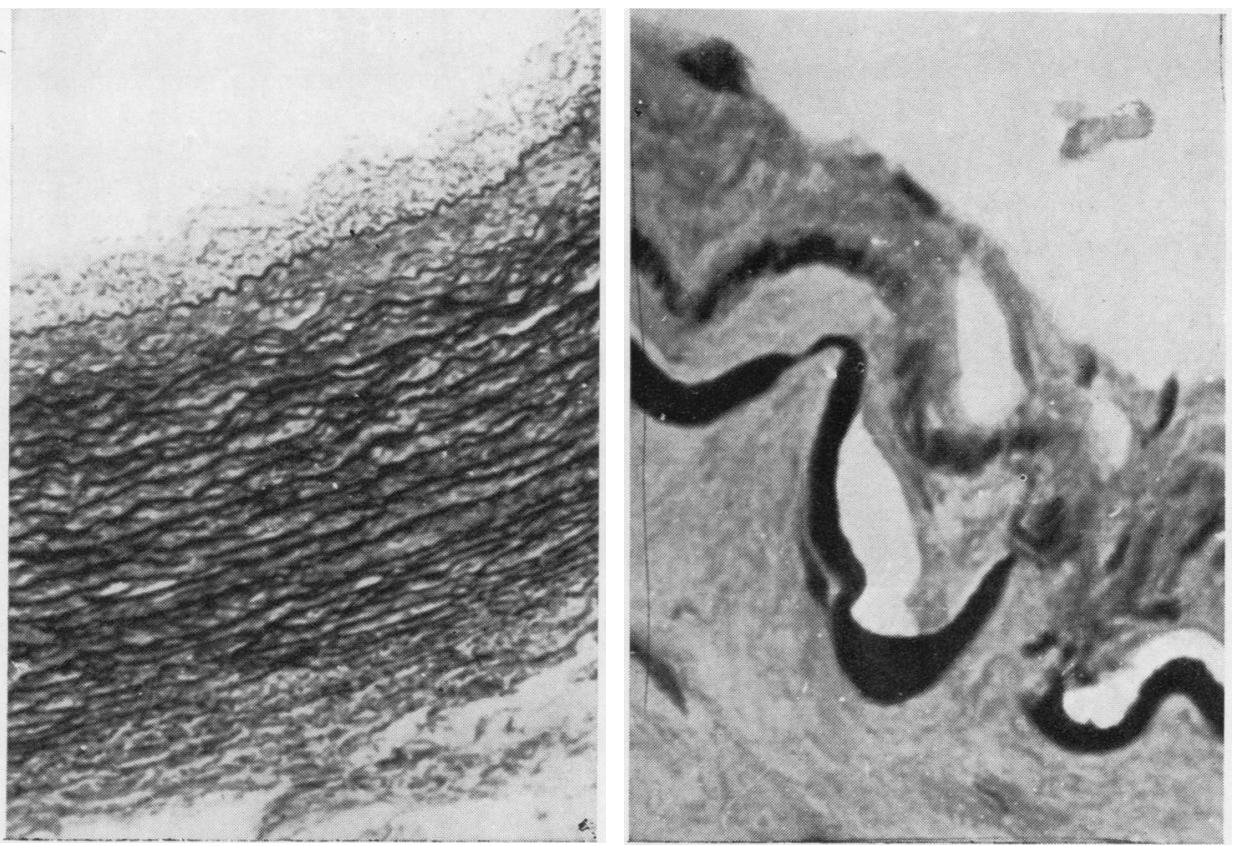

FIG. 7. Concentric increase in intima (carotid, 4 months). Verhoeff $\times 80$.

FIG. 9. A shadow layer in the intima, composed of elastin fibres (radial artery, 70 years). Verhoeff $\times 640$.

FIG. 9 


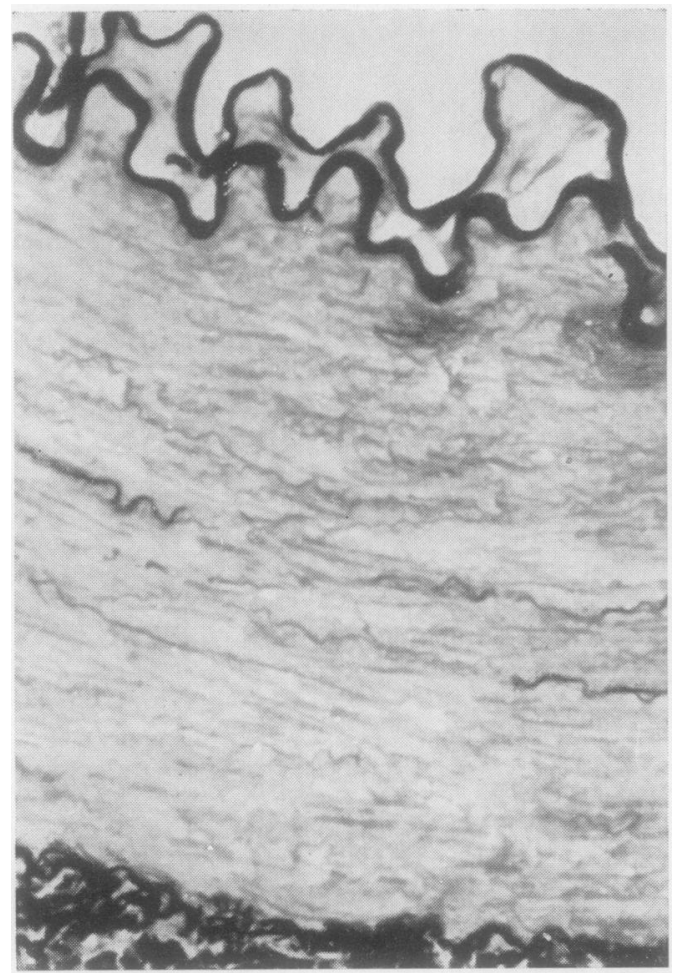

FIG. 10

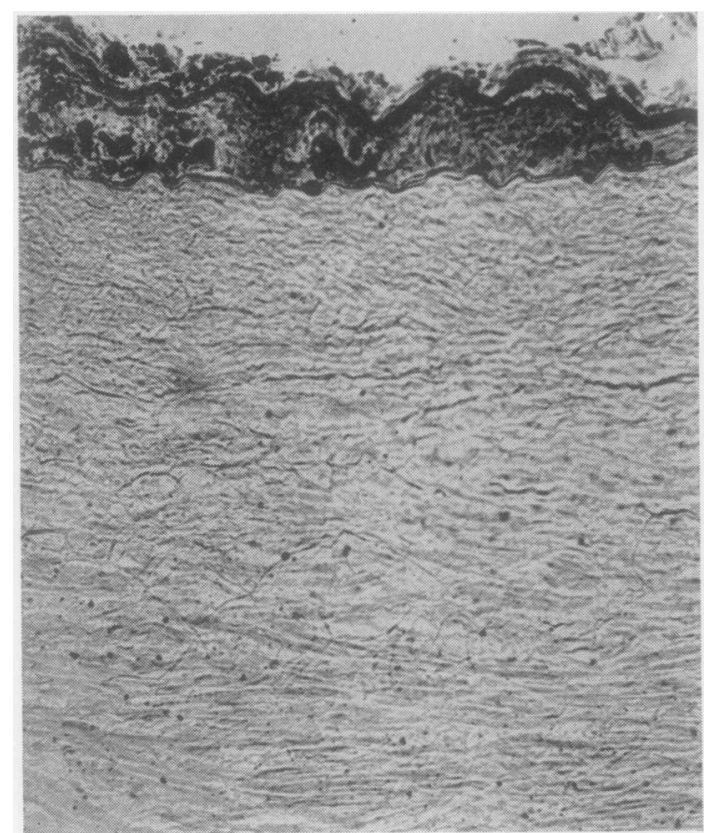

FIG. 12. Fat in the intima, on the lining layer, and between it and the internal elastica (femoral, 18 years). Sudan IV $\times$ 800.

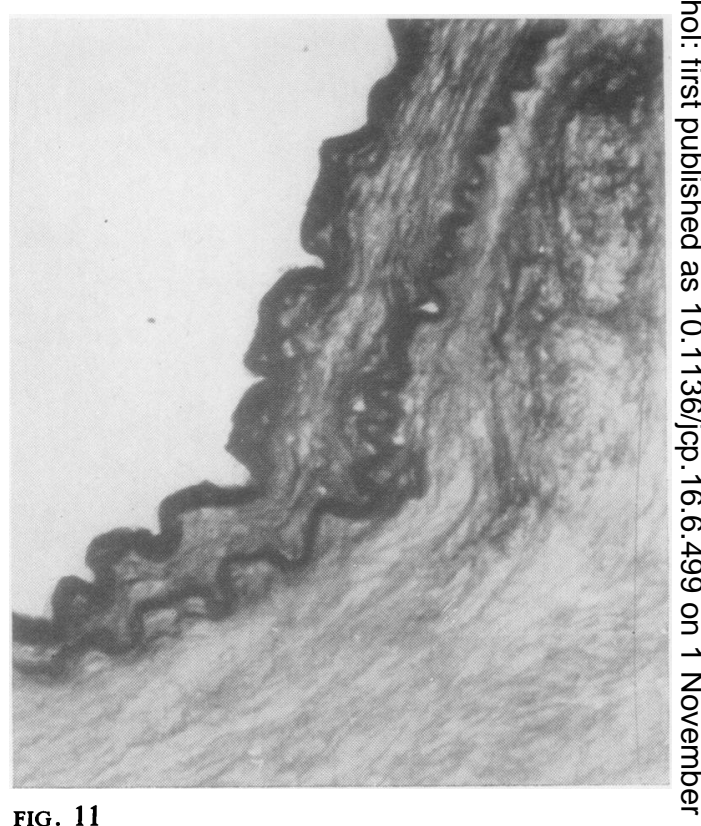

FIG. 10. The lining layer, resembling the internal elastif lamina, and separated from it by ground substance in which one cell nucleus is seen (femoral, 2 years). Verhoeff $\times 8000$ FIG. 11. Internal elastic lamina and lining layer (poplitea 12 years). Verhoeff $\times 400$.

thickened intima (Figs. 10 and 11); it is, however $\frac{\frac{\circ}{\Phi}}{2}$ more diffuse, less regular, and not so luminouslo eosinophilic as the internal lamina. It may be indis tinguishable with Verhoeff's stain, or may stain onl a pale grey; orcein stains the unequivocal elastic lamina brown but stains this new layer black. Sudae IV is taken up as the elastic lamina takes it up, and focally to a greater degree (Fig. 12). It does not stain. for fibrin. Loss of continuity of the internal laminæ appears by 2 years of age, and earlier in the femora and popliteal arteries. It is sometimes more striking on longitudinal sections. The total loss increases with age; where the loss is $15 \%$ at 12 years of age it may be as much as $30 \%$ by the middle thirties, and so great in old age that remnants of the true elastica are hard to find.

PATTERN IN ADULT LIFE For the large arteries af least, the normal adult picture is one of a con centric intima, with the second and even third layê resembling internal elastic lamina (Fig. 13). Loss of continuity of the deep internal elastic lamina is usua $\vec{F}_{\vec{b}}$

CALCIFICATION OF THE INTERNAL ELASTIC LAMIN One of the best examples of this is seen (Fig. 14) in the popliteal artery of a young man of 33 years. The characteristics are: blue staining on haematoxylig. 

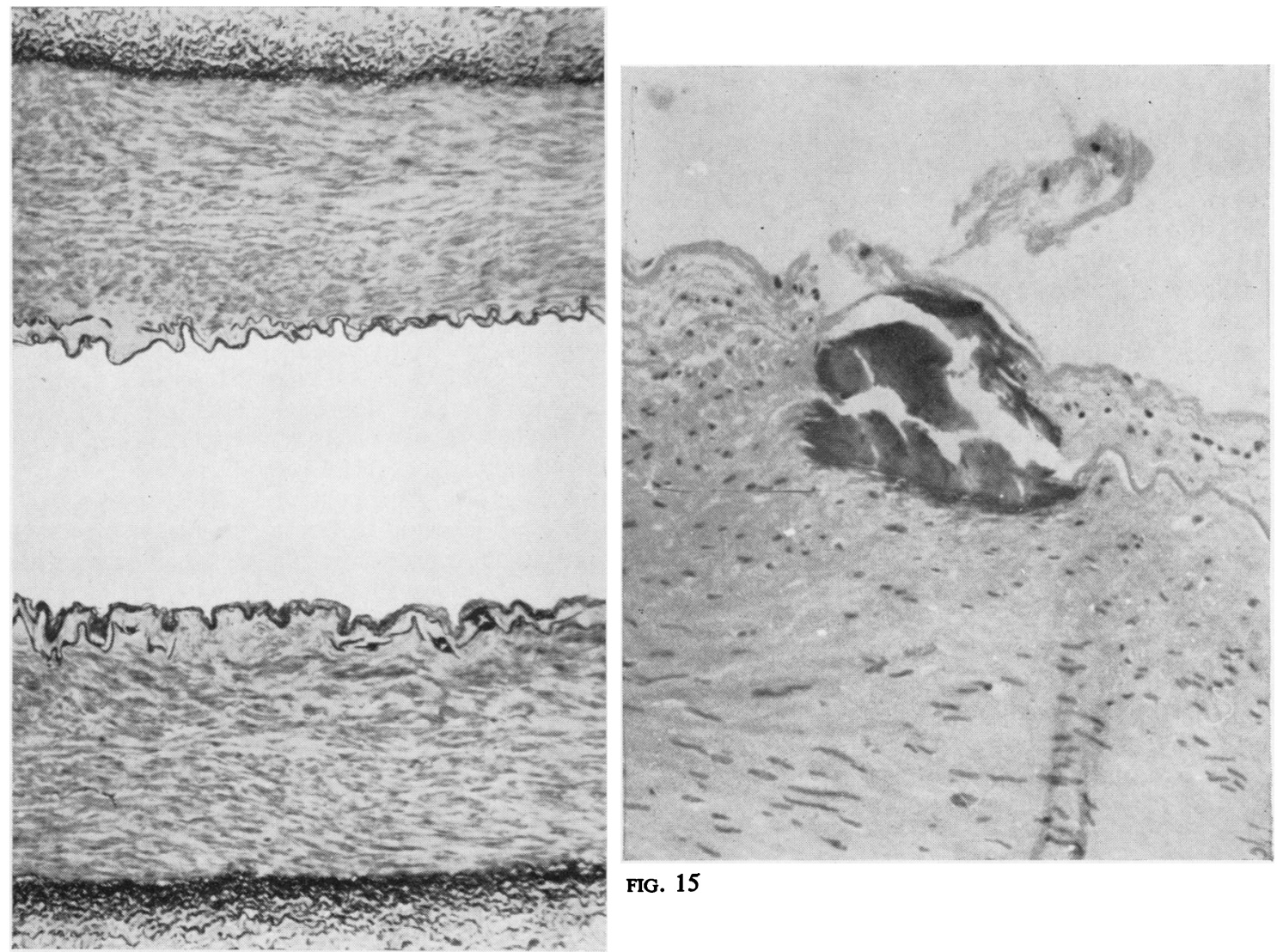

FIG. 15

FIG. 13

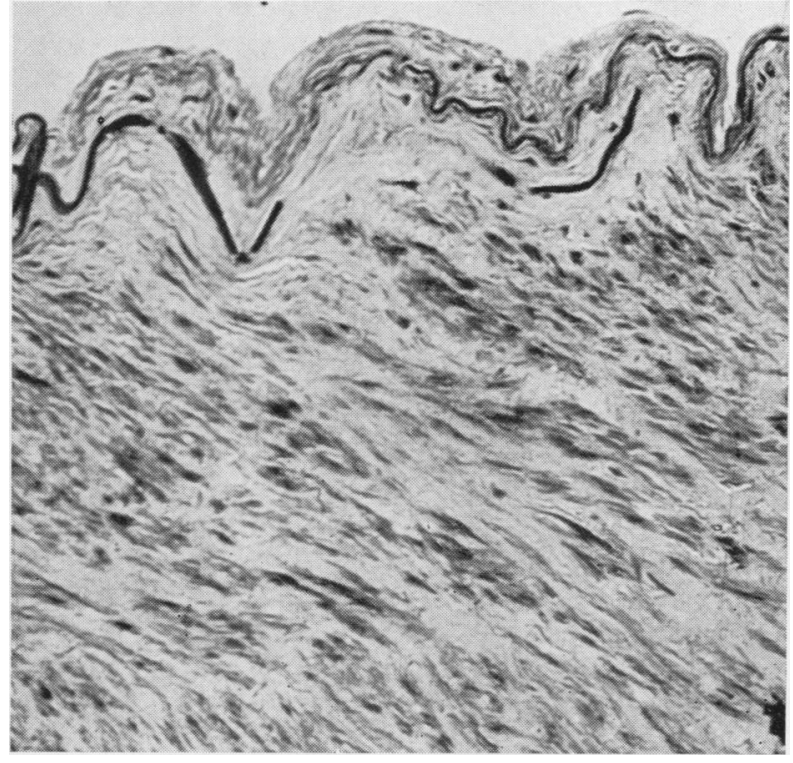

FIG. 13. A typical adult artery, in which the prominence of the lining layer obscures the internal elastic lamina which lies deep to it and shows loss of continuity in several places (femoral, 21 years). Verhoeff $\times 40$.

FIG. 14. Calcification of the internal elastic lamina (femoral, 33 years). Haematoxylin and eosin $\times 190$.

FIG. 15. Non-linear calcification of the internal elastic lamina usually commoner in the older age groups than the linear form (popliteal, 36 years). Haematoxylin and eosin $\times 160$.

FIG. 14 
and eosin or a short, straight length of lamina, usually adjacent to a small loss of continuity. Sometimes there is a similar piece on the other side of the gap, and occasionally the appearances of both suggest the disruption of a single piece of rather brittle material. The elastica in this area is surrounded by a noticeable pool of ground substance, usually resembling collagen in colour on the van Gieson stain, and sometimes intensely basophilic on haematoxylin and eosin but without fibres. There may be one or many of these short linear calcifications on one section: as appearances may be similar on the longitudinal sections, the lesion is presumably not linear, but involving an area of the lamina. It is typically confined within the borders of the lamina, and bears no obvious relationship to any other appearances of the artery wall, except a noticeable accumulation of the ground substance throughout the media and intima. It stains a brilliant emerald with Naphthochrome Green B, which is specific for calcium. It does not react in Perls's stain for iron. It does not stain for fat. Although it stains deep black with Verhoeff, and is indistinguishable from the elastica, it does not stain with orcein which is held to be a specific stain for elastin. It stains with carbol fuchsin but is not acid-fast. With the exception of the femoral artery of a girl of 3 years whose elastica showed such marked loss of continuity that it could not be regarded as normal, the youngest artery in which this change was found is the femoral of a man of 17 years of age. From this age onward it is often found in the femoral and popliteal arteries and from the age of about 30 consistently in both. It is seen in other arteries, usually at later ages, but not at all in the coronary, carotid, or digital arteries. Where there is more than one layer of apparent elastica, the deepest layer only is affected.

This does not, even in the 3-year-old child mentioned, really resemble the changes reported in hypervitaminosis D (Hass, Trueheart, Taylor, and Stumpe, 1958), in which the calcification may involve the whole lamina, nor those of other aetiologies (Moran and Becker, 1959). It does resemble Hass's (1943) axial crystallization, except for the site, and the different response to fat stains. It was first described by Matusewitz (1902) in material from a necropsy in 1896 on a 61-year-old man.

There is another form of calcification of the internal elastic lamina where the lesion is not confined within the borders of the lamina (Fig. 15). This is more noticeable in the older age groups. Both forms are very common in the vessels of the leg though not restricted to them.

Calcification of the internal elastic lamina shows no relationship to calcification of the media, the earliest sign of which is pin-point crystallization in the ground substance; no particular relationship is. seen to muscle cells. In an intermediate artery suc突 as the renal or superior mesenteric, fairly near the aorta, an affected area may be seen with an elastio fibre running through it, as yet uncalcified. The anterior tibial artery shows medial calcification at ap earlier age than other vessels: it is not usually foun $\mathbb{P}^{8}$ elsewhere till the 60 s or later. The radial artery is particularly affected but over 70 years of age this may be said to be a common change. The arteries of the brain are not exempt. The aorta and carotidsw do not appear to show this change. Formation of bone and even bone marrow has been mentioned in textbooks as a consequence of arteriosclerotiọ calcification. A section from a renal artery of a mans of 94 bears a superficial resemblance to bone ande bone marrow: giant cells are visible and this is of foreign body reaction following trauma and haemorr? hage at the edge of a plaque which may have fractured. It is not so much medial as a calcified area of atheroma (Fig. 16).

Calcification of the internal elastic lamina appears: to occur where there is a marked accumulation of the ground substance; this change is noticeable in theo popliteal and femoral arteries from the age of 25 ore 30 years and stains pink with haematoxylin and eosin at this age. Later it becomes lilac and then frankly basophilic. Hale's stain shows it to be acid mucopolysaccharide. Its distribution is uneven among the layers of medial muscle (Fig. 17). Where theD accumulation is very marked the muscle cells present an isolated and bizarre appearance (Fig. 18)응 As in normal arteries no ground substance is seen in the adventitia of these vessels.

Evidence of deposition on artery walls is some times found, as in the groups of foam cells (Fig. 19) on a normal intermediate renal artery of a boy of 120 years. Organizing mural thrombi are not uncommon: One was found in the femoral artery of a youngo woman of 18 who died of obstetric shock and post partum haemorrhage (Fig. 20). It shows no associa-윽 tion with any underlying appearance in the wall $\rightarrow$ which is in fact normal. Similar lesions have been seen in the popliteal artery of a man of 35 and in then radial artery of a man of 70 years. Later stages are? the crescentic cellular plaques, followed by classica 5 atheroma.

\section{SUMMARY OF RESULTS BY DECADE}

The first decade is divided into two groups: Groupo A consists of five cases varying in age from a 36-week foetus to 5 months (three females, two males), and? group B six cases aged from 2 to 9 years (three $\vec{\Omega}$ males, three females). 


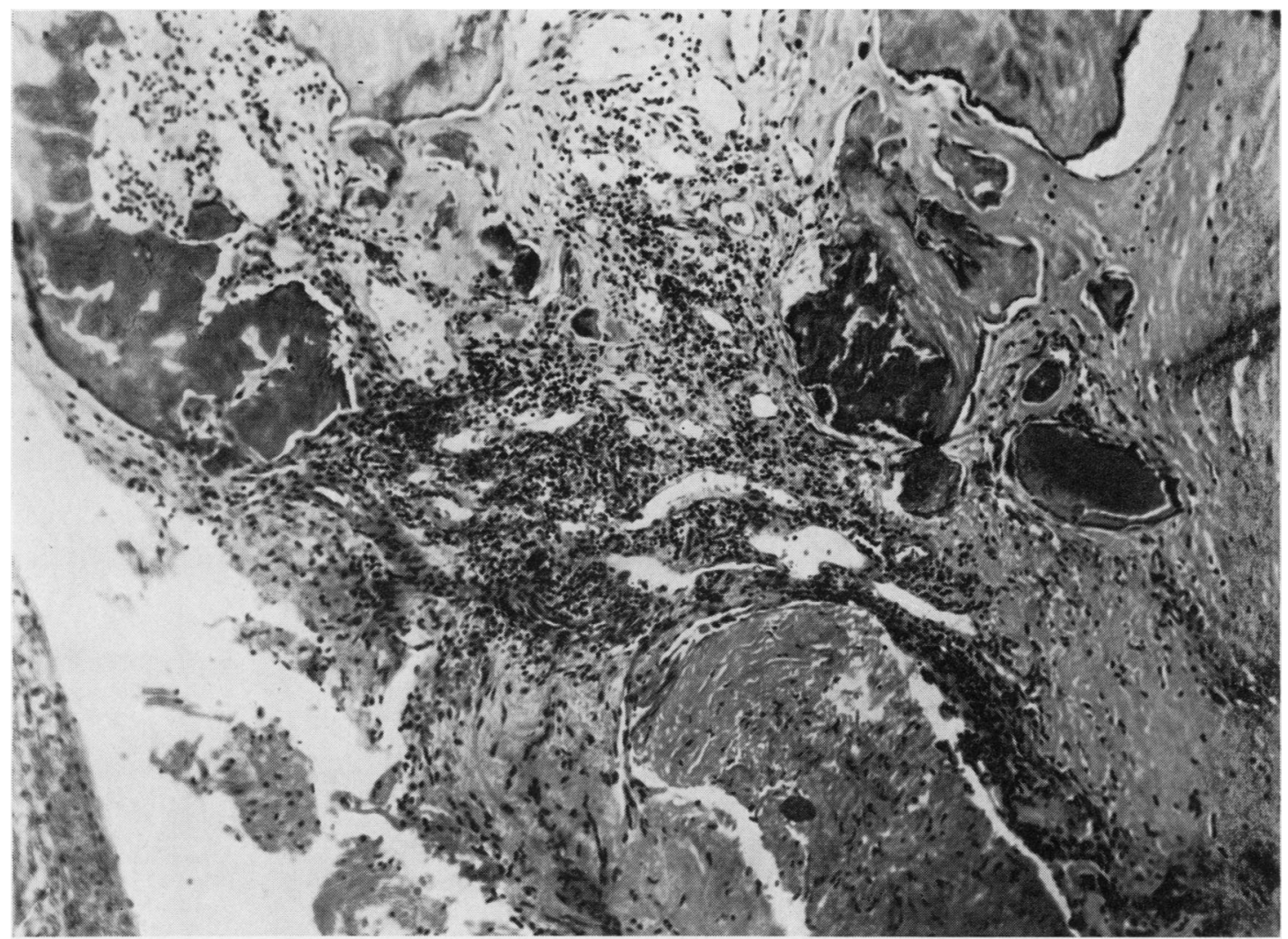

FIG. 16. Foreign-body reaction round a fractured calcified atheroma in the renal artery $(94$ years). Verhoeff $\times 95$.

GROUP A The aorta and coronary arteries in this group are normal except for one fibrous plaque above the aortic valve in the sole case of hypertension.

The carotid arteries are elastic in type. No intima is seen in the carotid of the 36-week foetus but concentric thickening is seen at 4 months.

The posterior communicating and vertebral arteries (one case) both show swelling and beading of the internal elastic lamina. In addition a small amount of elastin is present in the adventitia and media of both; none is usual in these sites. (This case was hypertensive.) The renal arteries are infantile as are the brachial arteries, one of which shows a musculo-elastic cushion clearly adjacent to a branch. The radial arteries are infantile with a slight excess of elastin in the media and adventitia in the hypertensive case. Four out of five femoral and three out of four popliteal arteries show musculoelastic cushions; one popliteal artery shows an appreciable intima in which longitudinal elastin fibres are seen. The only anterior tibial artery is infantile with a small eccentric patch of intima and a slight excess of elastin in the adventitia.
In the first six months the basic pattern is infantile with musculo-elastic cushions in the femoral and popliteal arteries and early intimal thickening in the carotid and popliteal arteries. One hypertensive child of 10 weeks shows a tendency to excess of elastin in the media and adventitia. No fat is present.

GROUP B All aortas and coronaries are normal except for a very slight streaking of the lower abdominal aorta of a boy of 9 years. A 2-year-old carotid artery shows concentric intimal thickening with a 'lining layer' resembling elastin and a 9-yearold artery shows some eccentric thickening. Some swelling and beading of the elastica is seen in vertebral arteries. Posterior communicating arteries are infantile. Renal arteries at 2 years are infantile with a suggestion of beading of the internal elastic lamina and at 9 years a musculo-elastic cushion is seen adjacent to a branch. The superior mesenteric artery from the same body shows some concentric intimal thickening. The brachial artery at 2 years is infantile in pattern; there is an unusual helical pattern in the adventitia. Of six radial arteries none is com- 


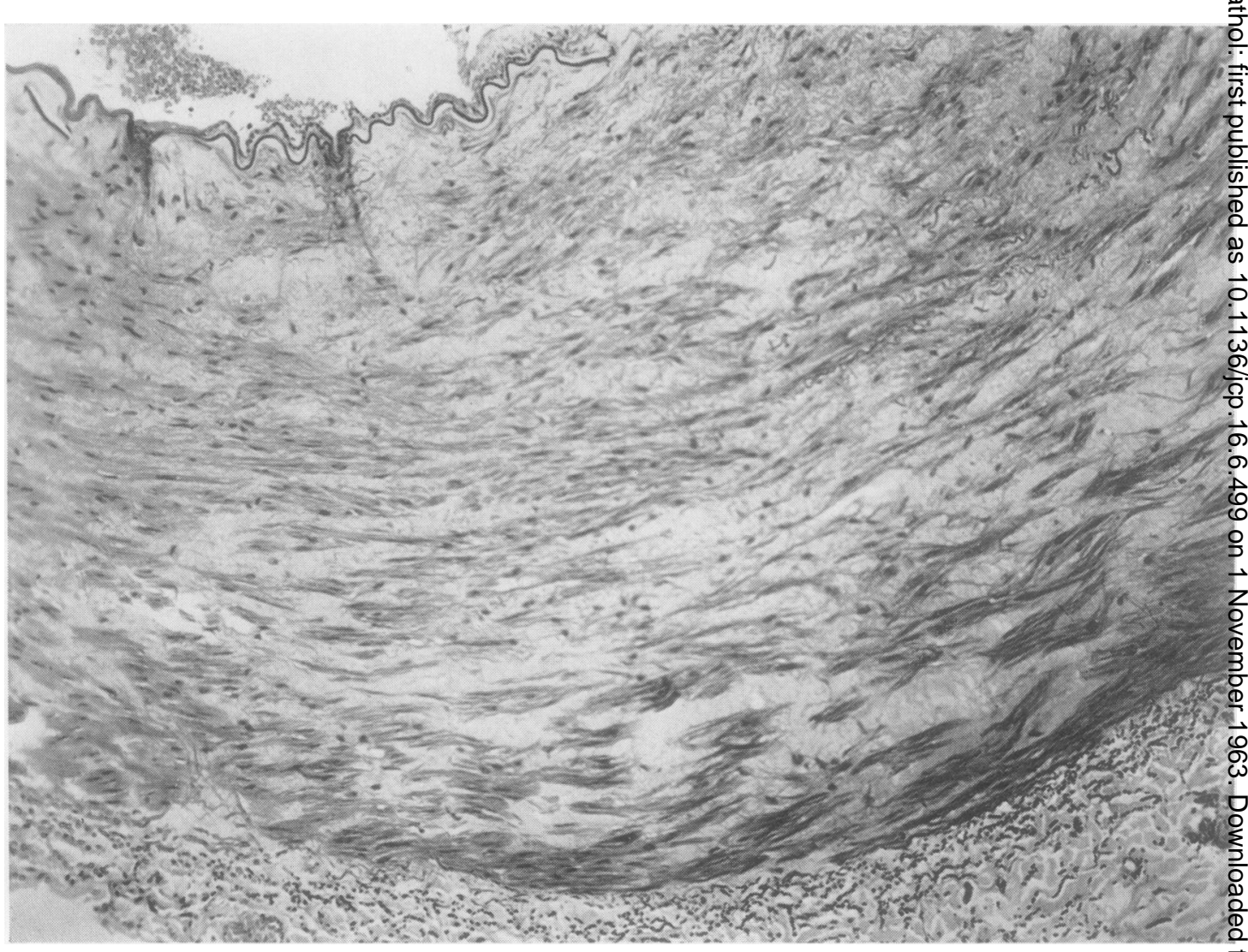

FIG. 17. Irregular accumulation of pools of ground substance throughout the media (femoral, 52 years). Haematoxyl产 and eosin $\times 95$.

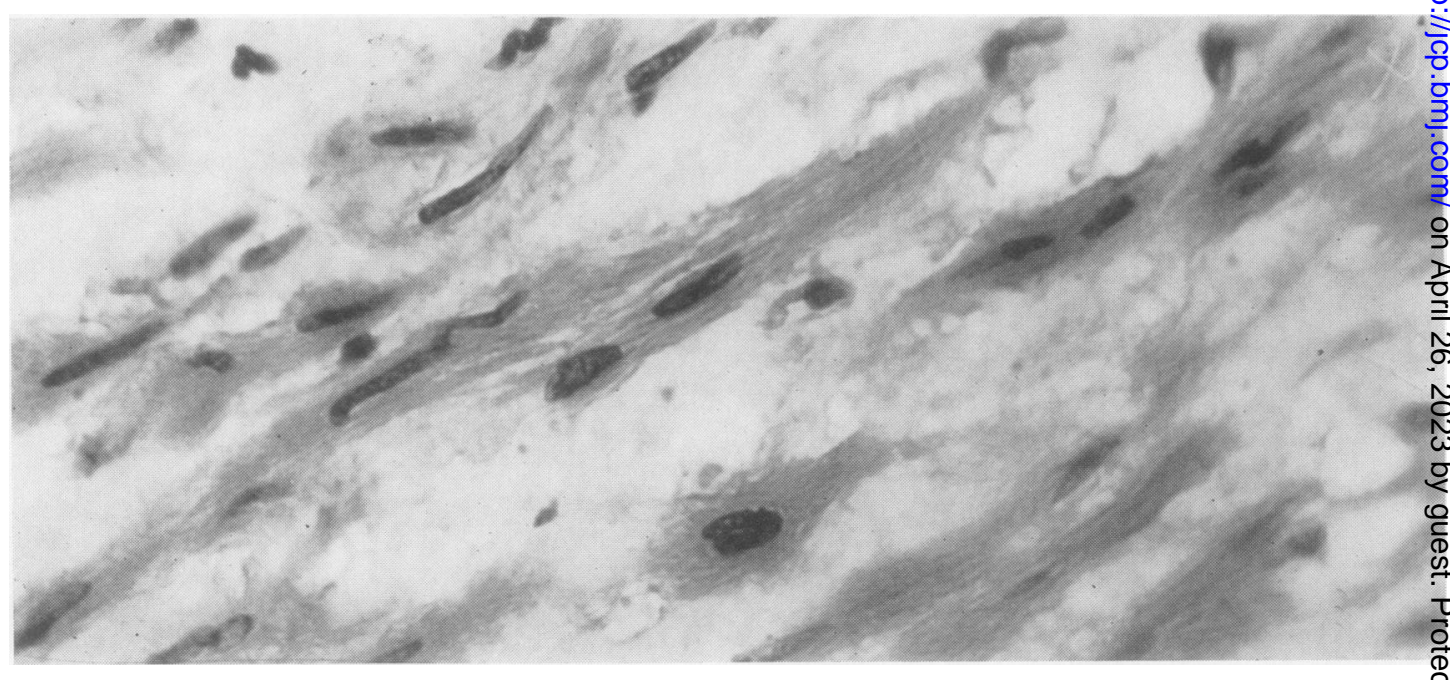

FIG. 18. Separation and disorientation of medial muscle cells by ground substance (femoral, 52 years). Haematoxy and eosin $\times 750$. 


\section{The microscopical appearances of human peripheral arteries during growth and aging}

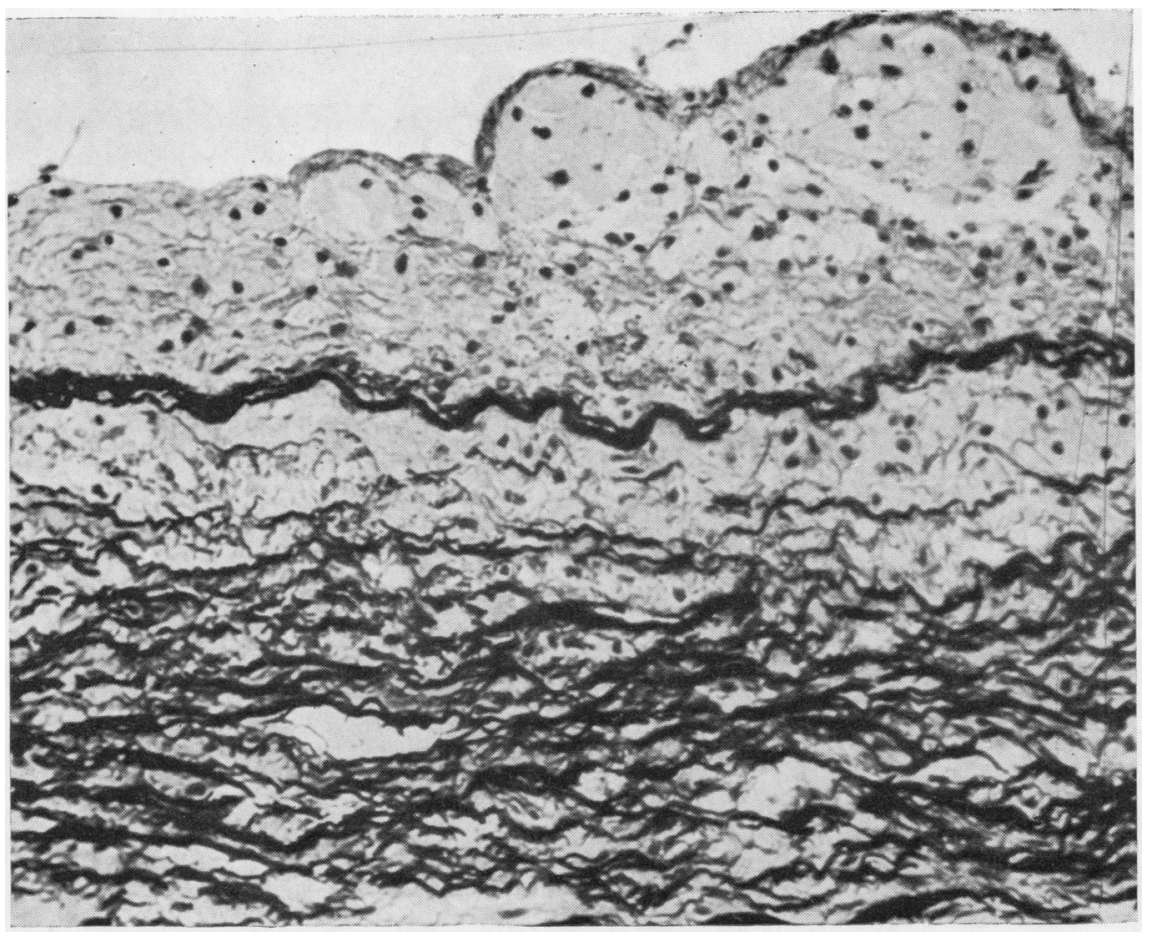

FIG. 19. Foam cells in the intima (renal, 12 years). Verhoeff $\times 200$.

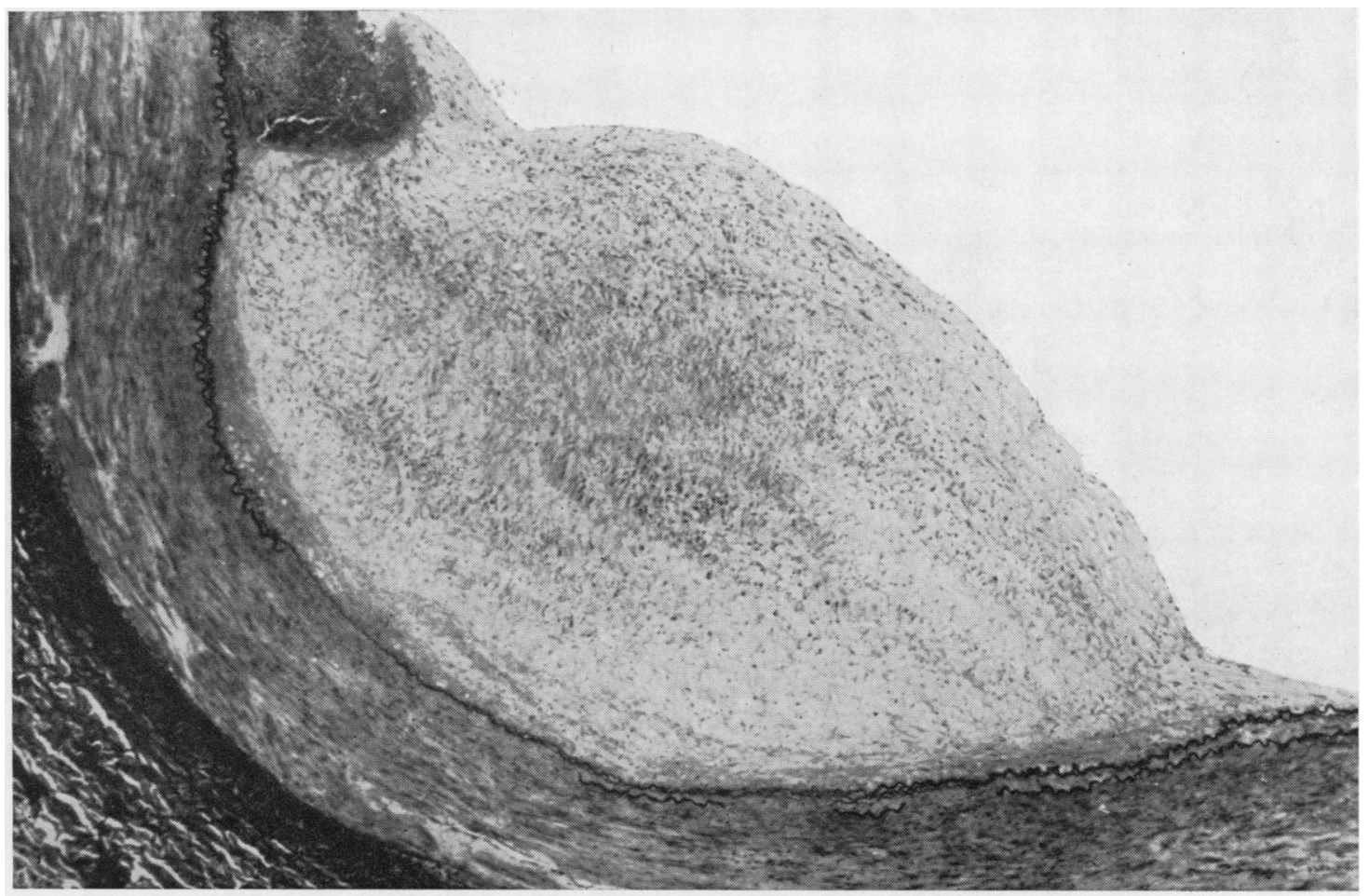

FIG. 20. Organizing mural thrombus (femoral, 18 years). Haematoxylin and eosin $\times 40$. 
pletely infantile; a lining layer is seen without other intimal thickening in the 2-year-old artery. In another $2 \frac{1}{2}$-year-old artery fenestrations are seen in the internal elastic lamina where the section gives a surface view of the lamina. Two radial arteries show cushions at branches and tiny losses of continuity of the internal elastic lamina in an otherwise infantile artery. No fat is present. Concentric intimal thickening is seen without loss of continuity in the internal elastic lamina at 4 years and at 8 years there is a 'lining' layer as well. Two plantar and two palmar digital arteries from children aged 2 and 9 years are infantile in pattern with some eccentric thickening of the intima associated with branching in the older. Of five femoral arteries, none is completely infantile in pattern, one has a 'lining' layer, and three show concentric intimal thickening; the artery aged $2 \frac{1}{2}$ years shows some eccentric thickening as well and the internal elastic artery shows the same type of fenestration as that from the radial from the same case. One case must be regarded as abnormal as nearly $80 \%$ of the internal elastic lamina is missing, some is calcified, and some is beaded and irregular; this artery also shows scanty elastica in the adventitia. At 8 years the internal elastic lamina is intact, the intima is an appreciable layer and a lining layer covers it. The intima contains no fat. Of two popliteal arteries (aged 2 and 9 years), each shows three very large cushions such as are associated with branching, and considerable intimal thickening in the 9-year-old artery. No measurable loss of continuity is seen in the transverse or longitudinal section; no fat is present. One anterior tibial artery aged 2 years shows an infantile pattern but the internal elastic lamina also shows fenestrations.

This group (aged 2 to 9 years) shows the emergence of a recognizable intima and of the 'lining' layer. Two cases in this group may well be abnormal, a 2-year-old artery presenting a helical appearance of the elastin in the internal lamina and in the adventitia, and a 3-year-old having a very marked loss of internal lamina.

The second decade is from 10 to 19 years and contains two females and four males, none showing hypertension.

Three of the aortas show fatty streaking; there is a fibrous plaque just above the aortic valve of a boy of 12 years and the media of this aorta contains a noticeable amount of mucopolysaccharide. All the coronary arteries are normal in appearance.

One posterior communicating artery aged 12 years is infantile in appearance containing no elastic tissue in the adventitia or media. All six vertebral arteries are infantile; swelling and beading of the internal elastic lamina is commonly present. All six carotid arteries show concentric intimal thickening. One brachial artery aged 12 years was available and. shows concentric intimal thickening with a clea lining layer. A radial artery aged 12 years shows concentric intimal thickening and a cushion of intima at a branch. Digital arteries aged 12 years are infantile. Three out of the six renal arteries are infantile in pattern. Two show excessive mucopoly saccharide in the media and two others proliferation of the musculo-elastin. The 12-year-old artery, के presumably incidental finding, has two groups of foam cells apparently on a normal arterial waltw both apparently covered by endothelium (Fig. 19) A superior mesenteric artery aged 12 years show $\$$ concentric intimal thickening. None of the six femoral arteries is infantile in character. The 10-year-old artery shows some concentric intimate thickening and a crescentic layer involving half the circumference. A lining layer is present. There is nब loss of continuity of the internal elastic lamina on transverse section but on longitudinal section smal\$ gaps are present and these are adjacent to the intima proliferation. No fat is present. The 12-year-ols artery shows concentric intimal thickening. The internal elastic lamina shows measurable loss of continuity; on transverse section there are 10 gap\& amounting to $2 \cdot 3 \mathrm{~mm}$. $(16 \%)$ of the circumference In a $10 \mathrm{~mm}$. longitudinal section there are 28 gap amounting to $21 \%$ of the length. No fat is present The 13-year-old artery shows a minimal intima and no loss of continuity on transverse section of the internal elastic lamina. On longitudinal section there are four gaps amounting to $8 \%$ of its length; some fine fat droplets are seen in the intima. The 17-year old artery shows concentric thickening of the intim in which fat is not present but there is a noticeable amount of ground substance. Loss of continuit in the internal elastic lamina amounts to $16 \%$ and $21 \%$ on transverse section and longitudinal sectio respectively. As in the intima, the media has $\&$ marked accumulation of mucopolysaccharide: the internal elastic lamina shows calcification which is linear and non-linear in type. The 18-year-old artery shows a thickening intima covered by a lining layer: Gaps in the unequivocal elastic lamina amount to $15 \%$ and $12 \%$, and excessive mucopolysaccharide is present in the intima and media. A large organizinf thrombus protrudes into the lumen from above the lining layer. Fat is seen in the deeper parts of the thrombus and to a lesser degree in the tissue betweeb the internal elastic lamina and the lining layer anf focally on the lining layer also (Fig. 12). The 199 year-old artery shows intimal and medial mucopoly=0 saccharide. The internal elastic lamina shows calciē fication and loss of continuity amounting to $28 \%$ o transverse section and to $13 \%$ on longitudinad section. One popliteal artery aged 12 years show 
concentric intimal thickening with some loss of continuity of the internal elastic lamina $(2 \%$ and $40 \%)$. One anterior tibial artery aged 12 years shows concentric intimal thickening with a lining layer and some loss of continuity of the internal elastica.

The smallest vessels are infantile; all the rest show concentric intimal thickening, loss of continuity of the internal elastica, and a new layer of doubtful origin, somewhat resembling elastic, lines the vessel. Mucopolysaccharide is seen in the media and intima of some large vessels. Calcification of the internal elastic lamina has appeared, and one organizing thrombus is seen, bearing no relationship to any underlying condition, lying apparently haphazardly on the vessel wall which contains a notable quantity of ground substance. Fat is seen only in this lesion and to a much lesser degree in the intima of this vessel. Some aortas in this group show very small fatty lesions and a few foam cells are seen very superficially in the intima of the renal artery of a boy of 12 years (Fig. 19).

The third decade extends from 21 to 28 years, and contains specimens from four males and four females, none of them hypertensive.

Six out of the eight aortas show fatty streaking. One, from a woman aged 21 , also shows a small plaque near the bifurcation. The microscopic appearance of the plaque shows it to be an organizing thrombus. Three out of the eight coronary arteries show minimal fatty streaking. Five of six carotid arteries show concentric intimal thickening. One shows foam cells incorporated in the most superficial parts of the thickened intima. One vertebral artery is infantile in appearance with some beading and swelling of the lamina. Five show concentric intimal thickening with some loss of internal elastica and a lining layer, and two nonlinear calcification of the internal elastica. Three posterior communicating arteries are infantile with some swelling and beading of the internal elastic lamina. One palmar and two plantar digital arteries show both concentric and eccentric intimal thickening with some loss of internal lamina. Two brachial arteries are almost infantile, one having minimal loss of the internal elastica. Of radial arteries, two are infantile, one with a cushion at a branch. One from a 21-year-old woman show minimal intimal and elastic changes but there is a non-linear patch of calcification of the lamina, as is seen in other arteries from this case. Of six renal and four superior mesenteric arteries, all show minimal changes of the intima and elastic lamina. One renal artery shows non-linear calcification of the internal elastic lamina; this case also shows these changes in other arteries. Of seven femoral arteries, six show some concentric intimal thickening with a loss of continuity of the lamina and a lining layer. Three show calcification of the lamina in linear and non-linear forms associated with excessive mucopolysaccharide. One shows an eccentric cellular plaque which contains fat and a notable amount of ground substance in the plaque and in the media. The muscle cells indeed appear isolated by this quantity of ground substance (Fig. 18). Fat is present in the intima in small quantities in some. Three popliteal arteries generally resemble the femoral arteries with calcification of the internal lamina and excessive mucopolysaccharide in the media and intima. One case shows an eccentric cellular crescent. Of two anterior tibial arteries, one is infantile and the other shows marked intimal thickening and some changes in the lamina.

In this decade a marked change appears, particularly in femoral and popliteal arteries, involving calcification of the lamina and the accumulation of ground substance in the media. Other changes include the presence of fat in the intima, an organizing thrombus near the bifurcation of the aorta, and crescentic cellular plaques in two femoral arteries. Loss of continuity of the internal lamina continues so that in the femoral artery the loss amounts to 5 to $28 \%$ on transverse section and 5 to $40 \%$ on longitudinal. The popliteal arteries shows similar percentages. This is the last decade uncomplicated by hypertension.

The fourth decade consists of arteries from five males and four females (one male hypertensive, one female hypertensive, and one male diabetic).

Of the aortas and coronary arteries four are normal. Two show minimal fatty streaking. One (hypoplastic) aorta has lipid plaques. The vessel of the hypertensive male shows little or very scanty atheroma; those of the diabetic show atheroma of both aorta and coronary arteries, the subject dying in fact of coronary occlusion. All nine carotid arteries show some degree of intimal thickening and in five, foam cells are present. Classical atheroma is seen in the renal artery as in all the available arteries from the diabetic. Eight vertebral and three posterior communicating arteries all show minimal changes. An excess of elastin is seen in the vertebral artery adventitia of the two hypertensives and in a 32-year-old woman for whom evidence of hypertension is absent. Fat is present on the swollen, beaded internal elastica of one case. Three brachial arteries show minimal changes and another calcification of the internal lamina. Three radial arteries show some concentric thickening and one shows an intimal cushion at a branch. In nine renal arteries and three superior mesenteric arteries there are minimal changes of the intima and internal lamina with accumulating mucopolysaccharide in the media in six renal arteries and in one superior mesenteric artery which also shows 
calcification of the lamina. All internal laminae in nine femoral arteries show calcification and all the mediae show excessive mucopolysaccharide. Concentric thickening is present in all with some eccentric cellular plaques. Atheroma is present in those of the hypertensive male, a non-hypertensive male, and the diabetic. Gaps in the internal elastic lamina average $15 \%$ on transverse section and $26 \%$ longitudinally. Fat is present in the atheromata but also between the internal lamina and the lining layer in the same arteries. It is notable that these two layers may be intact beneath an atheroma. Of three popliteal arteries, eccentric plaques are present in all, either as organizing thrombi or cellular plaques with foam cells and concentric thickening. All show calcification of the internal lamina and accumulations of mucopolysaccharide in the media. The gaps in the internal elastica are approximately 15 and $25 \%$. Of three anterior tibial arteries, one at 37 years of age shows calcification of the media. Calcification of the lamina is only seen in the case of the hypertensive female, several arteries showing this change. Mucopolysaccharide is notable in the media of two cases. Intimal thickening is concentric and also eccentric in two.

The fourth decade thus shows calcification of the internal lamina of every femoral artery examined, with similar changes in the popliteal and other large arteries less frequently. One anterior tibial artery shows medial calcification. Atheroma is seen in femoral and popliteal arteries containing fat but no cholesterol clefts except in the case of the diabetic; in only the coronary arteries of this case could the atheroma be described as occlusive. Only in the aorta in the same case was calcium deposited in atheroma with blood pigment and recent haemorrhage.

The fifth decade is represented by arteries from five males and one female. (Two males were hypertensive.) Three deaths were due to coronary occlusion and three cases were suicides in which the coronary artery disease amounted only to occasional plaques.

All aortas show some atheroma from one small lipid plaque to moderately severe. All six carotid arteries show foam cells in thickened intima, and in one case of coronary occlusion with no evidence of hypertension, an atheroma in which foam cells and macrophages carrying blood pigment is seen; evidence of recent thrombosis is also present. Of five vertebral arteries, four are almost infantile but for the presence of swelling and beading of the lamina, and are free from fat. The fifth, in a case of coronary occlusion and hypertension, shows intimal proliferation in which fat is seen. Of three posterior communicating arteries, two are infantile and one shows calcification of the internal lamina. Of three brachial arteries, one is almost infantile and two show calcification of the lamina and excessive mucopoly $=$ saccharide in the media with minimal intimats change. In three radial arteries there is minimato departure from the infantile pattern. Of digitalarteries, 믐 two palmar and two plantar show concentric intimas? thickening with a lining layer and some loss of continuity of the lamina. The plantar digital arteryo of a case of carbon monoxide poisoning, without hypertension, shows more marked changes. Of six renal arteries, one is infantile in type, four show excessive mucopolysaccharide in the media and intima, of which two also show calcification of the lamina, and one other concentric intimal thickening and a lining layer. Of three superior mesenterio arteries, two show thickened intima and one calcifieds elastic lamina and excessive mucopolysaccharide in the media. Of six femoral arteries, all showe calcification of the lamina, and excessive mucopoly $=$ saccharide in the media. One has a calcification of the media. Atheroma is present in four, severely in case of coronary disease and hypertension. The gaps in the internal elastic lamina in this case amount to $40 \%$. Fat is seen in the same case deep to the elastica. in the media and on the internal elastic lamina, as well as in the atheroma. Of three popliteal arteries, ${ }^{\omega}$ two show medial calcification and all show calci fication of the lamina. Atheroma is present in two s one of these was not a case of generalized atheroma Two anterior tibial arteries show calcification of the internal elastic lamina and accumulation of muco $\mathbb{Q}$ polysaccharide in the media and one medial calci fication.

This decade demonstrates increasing medialo internal elastic laminar changes, especially in the arteries of the leg and some other large arteries. There is also atheroma at many sites in those dyin of coronary artery disease. Mönckeberg's sclerosis is seen in one femoral, two popliteal, and one anterior tibial arteries.

In the sixth decade all subjects were hypertensive three severely so (two males and two females). Two patients died of coronary occlusion, one of subar achnoid haemorrhage, and one of carcinoma o. the colon.

All aortas show atheroma and severe lesions in the coronary arteries. One carotid artery show foam cells in the intima and excessive mucopolyew saccharide in the media. The others show considere able atheroma, severe in one case where much media has been destroyed by the plaque which has new vascular channels beneath it. Of four vertebral arteries, two show concentric intimal thickening with minor changes of the lamina and excessive mucopolysaccharide in the media and intima; one of the latter also shows calcification of the internal 
elastic lamina, the other, atheroma. The elastin of the adventitia in the severest hypertensive appears in excess of normal. Three posterior communicating arteries are all adult in type. Of three brachial arteries, two show an adult pattern of intimal thickening and some loss of continuity and a lining layer and one excessive mucopolysaccharide in the intima and media. Of three radial arteries, one shows only minimal intimal and laminar changes and two an accumulation of mucopolysaccharide in the intima and media and calcification of both the internal lamina and the media. Of four digital arteries, one palmar and one plantar show minimal changes only; two plantar arteries also a slight excess of medial mucopolysaccharide. Of four femoral arteries, atheroma is seen in one but all show excessive mucopolysaccharide and calcification of the internal elastic lamina. One of two popliteal arteries shows calcification of the lamina and an excess of mucopolysaccharide in the media and the other atheroma. Minimal changes are seen in two anterior tibial arteries and medial mucopolysaccharide with calcification of the internal lamina in another.

This decade shows two cases where almost all available arteries contain excessive medial mucopolysaccharide, and calcification of the internal lamina is common. Medial calcification is seen occasionally, affecting radial and vertebral arteries. Of the two cases dying of coronary occlusion, one has atheroma in femoral and carotid arteries and the aorta but not in vertebral or renal arteries, while the other is remarkably free of generalized atheroma, only the carotid being affected as well as the left coronary artery.

The seventh decade was represented by five males and two females, all hypertensive (one severe) and one case of myxoedema. Coronary thrombosis was the cause of death in two.

All aortas and coronary arteries show atheroma. Of seven carotid arteries, all show atheroma and in two the plaques are large and collagenous, at least in the superficial layers. Four of seven vertebral arteries are typical adult arteries with minor intimal and elastic lamina changes and one shows excessive mucopolysaccharide. One artery shows atheroma, and another atheroma with cholesterol and calcium and collagen in the superficial layers; this artery also shows medial calcification. Minor changes only were seen in seven posterior communicating arteries. Of six brachial arteries, four show minor changes only, and two have excessive medial ground substance with calcification of the internal lamina in one. Of seven radial arteries, that of the case of myxoedema show occlusive atheroma with many foam cells, cholesterol clefts, calcium and collagen, and recent thrombus formation as well as medial excess mucopolysaccharide. Three show minor changes only and the remainder calcification of the internal lamina and of the media in one. Of the digital arteries (five plantar, two palmar), all show minor changes including some eccentric intimal thickening and minor loss of continuity of the internal elastica. None show accumulation of ground substance in the media. Of seven renal arteries, five show excessive medial mucopolysaccharide, even in one case where there is an infantile type of intima and lamina. One artery shows a cellular eccentric plaque, and atheroma is seen in two and is occlusive in one of them. Of six superior mesenteric arteries, five show medial accumulation of ground substance. Four show atheroma which is occlusive in one. Considerable amounts of collagen are present in all four. In seven femoral and six popliteal, all show atheroma, occupying more than one quarter of the lumen in two cases, including the case of myxoedema. All show accumulation of ground substance and calcification of the internal elastic lamina. Calcification of the media is seen in three cases. Of five anterior tibial arteries, two show atheroma, and in the case of myxoedema it is completely occlusive with small vascular channels and great destruction of the media. In the others ground substance is accumulated, three showing calcification of the internal lamina and of the media.

The seventh decade shows cases in which nearly every vessel has an accumulation of ground substance in the media and intima, with calcification of the lamina in all lower limb vessels and large vessels elsewhere. Calcification of the media is also seen in the vessels of the leg, and in one radial and one vertebral artery. There is a tendency for the atheromata of one body to be at similar stages where perhaps all show altered blood pigment, collagen, and evidence of recent thrombosis, as well as cholesterol and calcium. Most of the atheroma seen in cases of this decade contains a large proportion of collagen. The original internal elastic lamina is sometimes difficult to find.

The eighth decade consisted of arteries from four males and one female, three severely hypertensive and one diabetic.

All aortas, coronary, and carotid arteries show atheroma. The coronary arteries of the case of atheromatous aortic abdominal aneurysm show only fatty streaking. Two carotid arteries show an excess of ground substance in the media and intima. Of five vertebral arteries, two show atheroma and excess mucopolysaccharide. In five posterior communicating arteries minor changes only are seen, except in one case with atheroma and loss of internal elastic continuity. Of five brachial arteries, all show excess medial and intimal ground substance and two calcification of the internal elastic and of the media. 


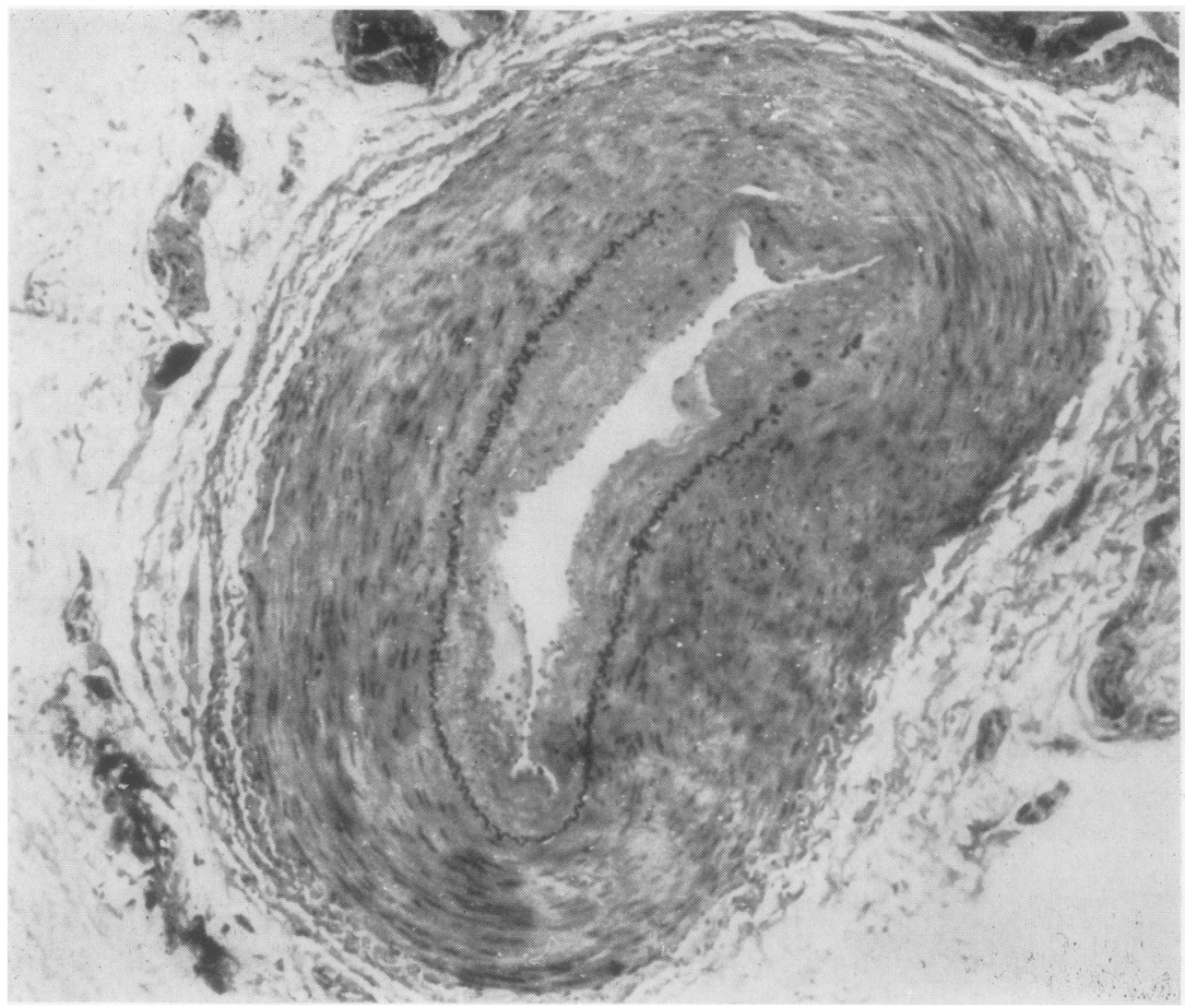

FIG. 21. Greatly thickened intima in old age, with intact internal elastic lamina for most of its circumference (palmar digital, 70 years). Verhoeff $\times 40$.

Three contain atheromata. Five radial arteries all show medial accumulated ground substance, with minimal intimal and laminar changes. An organizing thrombus and medial calcification are present in one of them, and atheroma in another. Of four digital arteries, three have excessive mucopolysaccharide in the media, one also showing medial calcification. All show some intimal thickening and in one there is a suggestion of collagen (Fig. 21). Five renal and five superior mesenteric arteries all show excessive medial ground substance, and one medial calcification. Three contain atheromata. Five femoral and five popliteal arteries all show atheromata, medial excess, mucopolysaccharide, and calcification of the internal lamina. Three show medial calcification. All are considerably dilated with stretched mediae and the atheromata contain evidence of layers of successive lesions, mostly collagenous.

The main difference from previous decades is in the collagenous, layered appearance of the atheroma of the large vessels, which are dilated and contain scanty medial muscle cells. The strength of the arterm wall appears to lie in the atheroma, encircling the lumen, and in the adventitia.

The ninth decade was represented by one male and one female, both hypertensive.

All vessels show excessive medial mucopolyo saccharide. Medial calcification is seen in the vertebral, renal, superior mesenteric, femoral, popo liteal, anterior tibial, and plantar digital arteries of one case. The other case shows less medial calcifio cation and more atheroma, including a nearlos occluded renal artery. Plantar and palmar digitat arteries show very considerable intimal thickening collagen being present in one, and the others appeaf to have considerable quantities of ground substance in the intima. All the large vessels are dilated.

In the tenth decade was one male not severely hypertensive.

The least changes are found in the posterio communicating artery, in which the intima is thicf and collagenous, though the internal elastic lamina 
is intact and single. No elastin is seen in the media or adventitia. All other arteries show accumulated ground substances in the media and intima, with calcification of the media in the vertebral, carotid, and leg arteries. Atheroma is found in vertebral, carotid, renal, and leg arteries, and is calcified. The renal artery shows a remarkable picture with a superficial resemblance to bone. In fact, calcified plaques of atheroma have fractured and are surrounded by inflammation and healing: lymphocytes, polymorphs, and giant cells are present and many new vascular channels. Much of the media has disappeared but here and there the internal elastic lamina is recognizable.

\section{TABLE I}

AVERAGE AGE IN YEARS OF MAIN ARTERIAL CHANGES

$\begin{aligned} & \text { Calcification of } \\ & \text { Internal Elastica }\end{aligned}$ Mönckeberg's Atheroma
$\begin{aligned} & \text { and Accumulation } \\ & \text { of Medial Ground }\end{aligned}$
Substance

\begin{tabular}{llll}
\hline Femoral & 30 & 70 & 45 \\
Popliteal & 30 & 70 & 45 \\
Anterior tibial & 40 & 45 & 60 \\
Carotid & -5 & 60 & 45 \\
Vertebral & 50 & 70 & 50 \\
Renal and superior & & & \\
mesenteric & 50 & 60 & 70 \\
Brachial & 50 & 60 & 60 \\
Radial & 50 & 75 & -80 \\
Digital & 75 & 80 & 80 \\
Posterior communicating & 55 & &
\end{tabular}

Table I shows the average age at which the main changes were found. There is no suggestion that any of the lesions at one site were related to another, but it seems clear that some arteries are prone to the development of certain lesions consistently earlier than are others.

\section{SUMMARY OF RESULTS BY ARTERY}

CAROTID ARTERY The elastin network amounts to about $30 \%$ of the media and 10 to $20 \%$ of the adventitia. The appearance of a concentric intima was first seen in a child of 10 weeks when the internal elastic lamina is intact and separate from the medial elastin network. Longitudinal elastin fibres are seen in the intima, especially in the thicker parts and in the media. The intima contains few cells, mostly muscle cells, arranged longitudinally. By 9 years a similar picture is seen, with a loosely cellular intima and longitudinal elastin fibres. Foam cells were first seen at 25 years and not infrequently after that age. Crescentic cellular plaques were first seen at a similar age and classical atheroma from the fifth decade, except in a diabetic who died of coronary occlusion at 39 years. Calcification of carotid atheroma, though common in the older age groups, is not universal.

VERTEBRAL ARTERY Minor changes only are seen up to the end of the second decade, though a beaded and swollen appearance of the lamina may be seen earlier and throughout life. This lamina and the intima only contain fat when atheroma is established in other arteries. Calcification of the internal lamina is seen infrequently from the fifth decade, and medial calcification not until the sixth. Atheroma is fairly common from the fifth decade.

POSTERIOR COMMUNICATING ARTERY In four cases (all hypertensive) this artery was atypical, being of unduly small calibre. In all but one the appearances of the artery were infantile, with no elastin in media or adventitia. In the fourth, intimal proliferation, beading and swelling of the lamina, and excessive elastin, amounting to $40 \%$ of the adventitia, were found.

In normal posterior communicating arteries, an infantile pattern may be found as late as the fifth decade, but in general the adult pattern is one of minor change. Eccentric intimal proliferation may be seen from the fifth decade onwards but atheroma was only seen in two cases, aged 78 and 80 , both of which had generalized atheroma and were hypertensive. Calcification of the internal elastic lamina was seen in one case aged 21 years, in which this condition was widespread. Similarly, excessive medial ground substance was seen only in those cases in which it was a general feature.

BRACHIAL ARTERY The infantile pattern may be seen into the third decade, and usually the adult pattern of intima, containing ground substance, a few muscle cells, and a lining layer which resembles elastica, appears in this decade. Loss of continuity of the internal elastic lamina is seen in the fourth decade. Cellular crescents and atheromata are rare, as are calcification of the lamina and media.

RADIAL ARTERY Minimal intimal thickening may be seen in infancy, and moderate proliferation by 2 years of age, accompanied by the appearance of a lining layer. Intimal thickening may be pronounced by the fifth decade, and atheroma is seen infrequently from the sixth, and more frequently from the eighth and ninth decades. One organizing thrombus was seen in a subject aged 70 years. Calcification of the lamina was first seen at 50 and of the media at 70.

DIGITAL ARTERIES Some intimal thickening is seen in the third and fourth decades, being marked by the 
fifth, and more in the plantar than in the palmar arteries. Some new elastin fibres are seen in the intima and loss of continuity is seen from the fourth decade. Excessive ground substance is seen in the media only where this is a generalized change: this is also true of calcification of the internal lamina and the media. No actual atheroma is seen, though the thickened intima appears collagenous from the seventh decade.

RENAL AND SUPERIOR MESENTERIC ARTERIES After the age of 25 , some concentric intimal proliferation may be found, containing new elastin fibres, and there may be a lining layer, though this is not common till the fifth decade, by which time the internal lamina may show marked loss of continuity. Calcification of the internal lamina, and accumulation of medial ground substance is fairly common from $\mathbf{5 0}$ onwards but medial calcification is found only in the $70 \mathrm{~s}$, in cases where there is a general tendency to this change. Apart from the diabetic case, atheroma was not seen before 60 years of age, and is only rarely occlusive, and then in generalized atheroma.

FEMORAL AND POPLITEAL ARTERIES The musculoelastic cushion is characteristic of infancy and childhood and is not seen after adolescence. The usual adult pattern with a loosely cellular intima and covered by a lining layer is seen in the femoral artery but in the popliteal artery the new layer is usually of compact, longitudinally orientated muscle cells, so that the whole layer resembles media. During the third decade, medial ground substance accumulates and calcification of the internal lamina appears. Mönckeberg's sclerosis is not seen till the end of the seventh decade. Fat is not seen, apart from very tiny droplets in endothelial cells, until there is a proliferated intima and some additional eccentric deposit such as the organizing thrombus previously described in a woman of 18 , or the intimal proliferation at the mouth of a branch. In these arteries, there are small quantities of fat in the intima, focally on the lining layer, more than on the internal elastic lamina, and often in one or more foci on the circumference of the lumen, as well, of course, as the larger quantity deep in the organizing thrombus.

Longitudinal muscle bundles are almost exclusively found in the popliteal artery, and vary from two or three separate small bundles to a complete ring between the internal elastic lamina and the circular muscle of the media, and are as large as the circular muscle.

ANTERIOR TIBIAL ARTERY This artery resembles the radial in the thickness of the medial muscle layer, rarity of atheroma, and proneness to Mönckeberg's sclerosis. It suffers earlier from calcification of the internal elastic lamina and accumulation of mediati ground substance.

DIGITAL ARTERIES These show some intimal pro을 liferation and occasional loss of continuity of the internal elastic lamina; the proliferation may be if such a form as to leave the lumen in the shape of क⿻ Maltese cross. In the seventh decade, there may be a solid collagenous layer between the internal lamina. and the lumen but no atheroma has been seen $\overrightarrow{E \omega}$ Excessive medial mucopolysaccharide and calci fication may be seen in the eighth decade, witlo calcification of the lamina, especially in cases wher these are common changes.

INCIDENCE AND DISTRIBUTION OF ATHEROMA

It is clear that atheroma is found in all except the smallest arteries, and that the number of sites affected increases with age. It is common in thep large vessels, and may become confluent in the femoral and popliteal arteries in old age. General ized atheroma does not necessarily imply occlusive disease: occlusion only occurs in cases in which the् cause of death is severe atheroma or myxoedema While it appears generally true that in deaths due too coronary disease atheroma is found in all larges vessels, one case described here is an exception, ing that only the left coronary and right carotid were्ष affected, and both severely.

In the one case of untreated myxoedema, the dis $\overrightarrow{0}$ tribution of atheroma differed from that in the rest of the series, in that occlusive atheroma was pre? sent in the popliteal, anterior tibial, and radia? arteries (Fig. 22).

Cases in the fourth and fifth decades were classifie of as normotensive or hypertensive; the femoral and vertebral arteries showed no difference in the incidence of atheroma. Probably all cases over $50 \mathrm{~B}$ years of age in this series were hypertensive in somes degree, but the mean number of arteries affected by? atheroma is similar in moderately and severelyo hypertensive groups.

\section{THE ELASTIN}

The most prominent elastic tissue in the artery wall is the internal lamina and the network in the adventitia; intimal and medial elastin is also presente in adult arteries at least. The intimal elastin is firstos? recognizable as longitudinal fibres in proliferating intima, seen in large numbers, and often in the presence of very few cells. These fibres are sometimes. seen (Fig. 23) closely adherent to the intimal surfacee्षे of the lamina. They are not prominent when single 


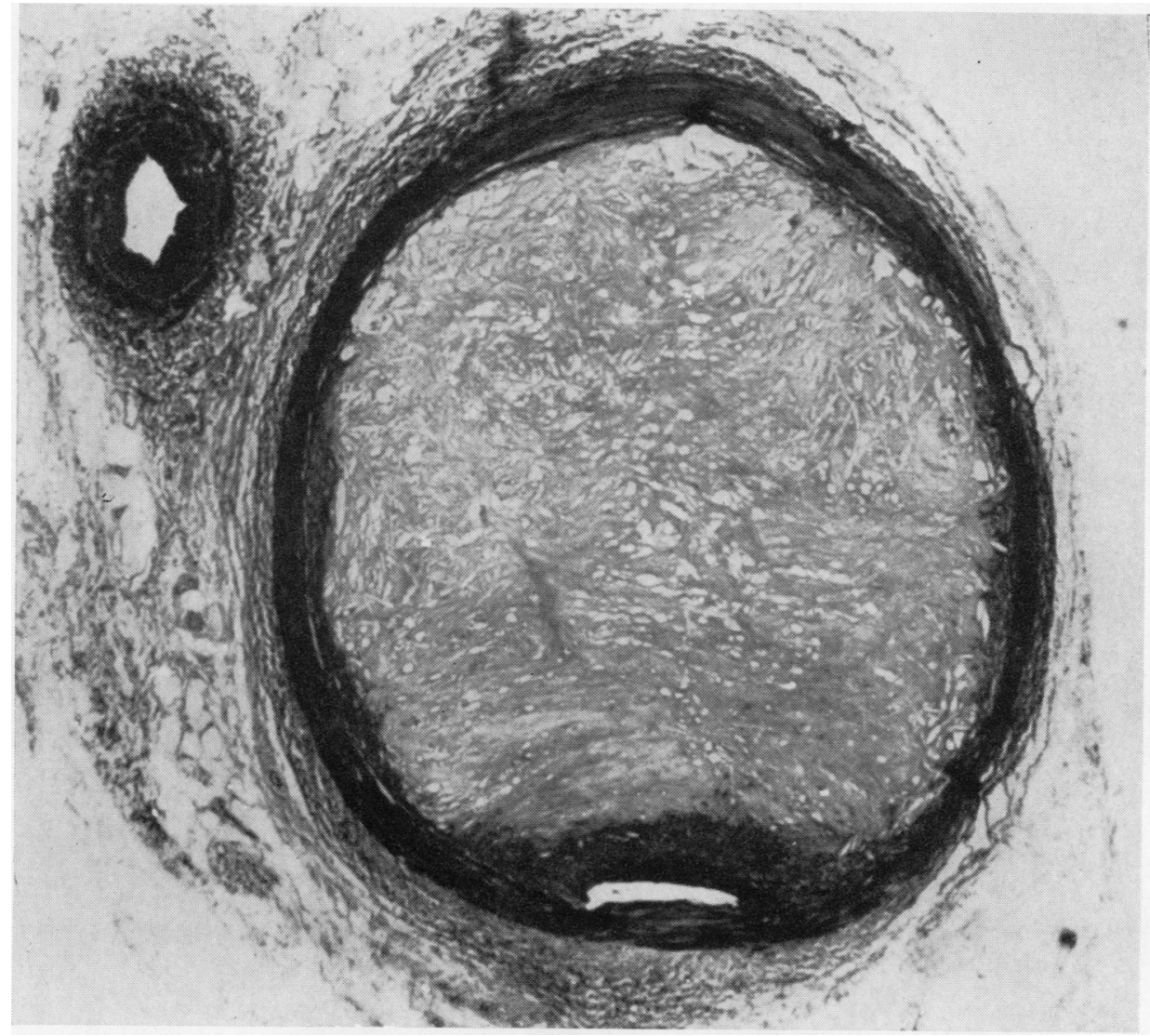

FIG. 22

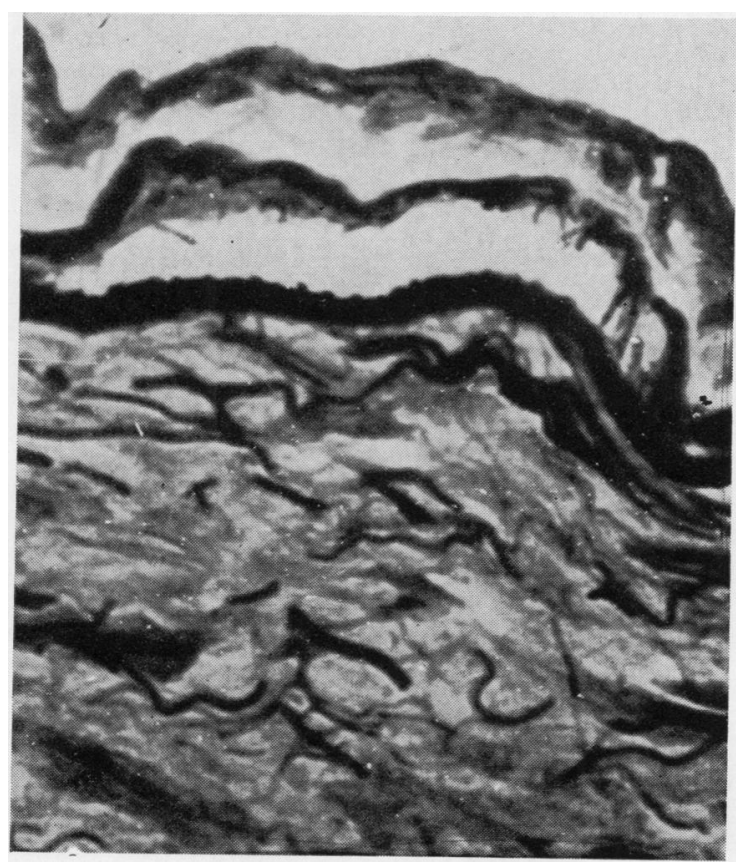

FIG. 22. Occlusion in myxoedema (anterior tibial, 67 years). Verhoeff $\times 10$.

FIG. 23. Longitudinal elastin fibres on the intimal surface of the internal elastic lamina (femoral, 52 years). Verhoeff $\times 640$.

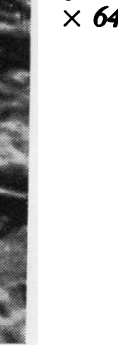




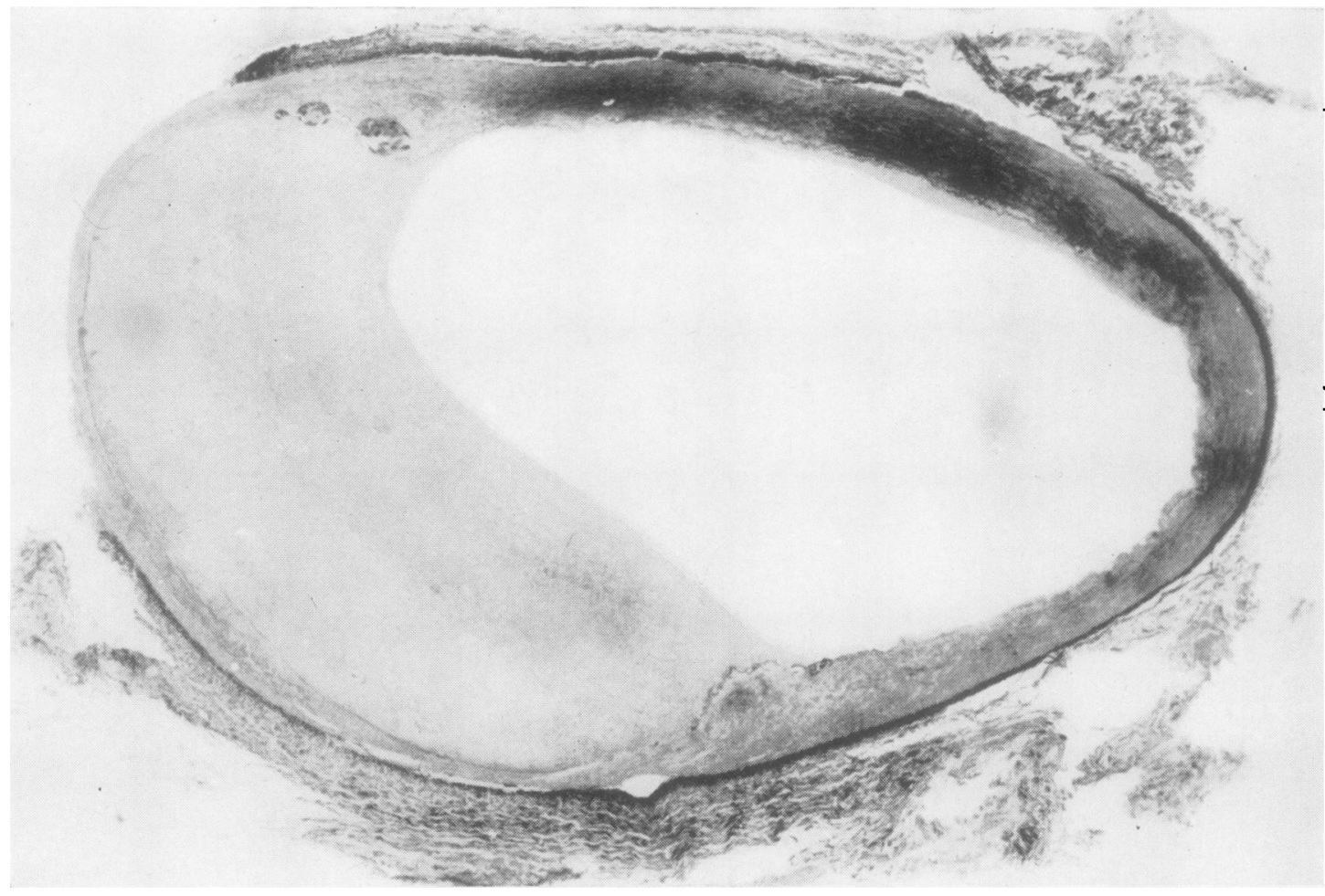

FIG. 24. Atheroma stretching and thinning part of the media. Note the course of the internal elastic lamina at the sides o the plaque and beneath it. Calcification is present in the media and in the internal elastic lamina (femoral, 47 years)。 Verhoeff $\times 10$.

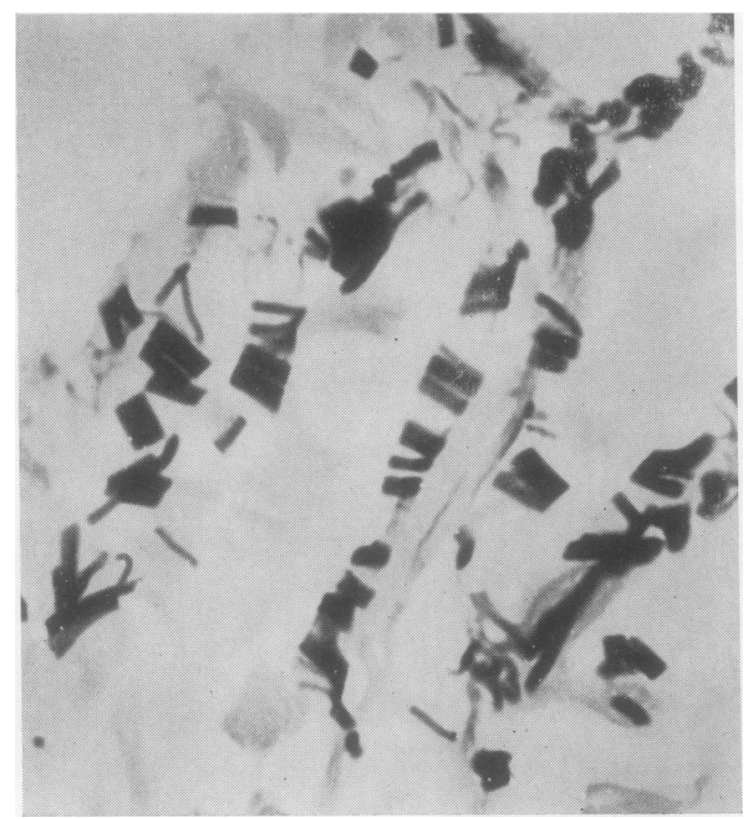

FIG. 25. Adventitial elastin helices (anterior tibial, 61 years). Verhoeff $\times 640$. but more so when arranged in a palisade (Figs. 8 an $\overrightarrow{\vec{\Phi}}$ 9); they are considerably thinner than the lamina? In adult vessels intact laminae are seen between the internal elastic lamina and the lumen; these resemble. elastica with most stains, and are almost alwaye thinner than the internal lamina. There may be morethan one such layer, focally if not entirely round the intima, and, indeed, the layers may vary in numbeo over the short distance involved in cutting a fewe sections further down the block. Appearances suggest that the lining layer becomes stretched and thinned and itself submerged in the intima. Calcifio cation of these layers does not commonly occur butw may do so very rarely.

Where a large atheroma is pressed into the arters wall the media may be thinned or even focall $\mathbb{L}_{0}$ destroyed (Fig. 24); the internal elastic lamina, oD its remains, may be recognizable at least on either side of the lesion, where it may be seen dipping down sometimes almost at right angles to its normas? course: destruction of this and of the intimal layers of elastin may, however, give an appearance suggestiv $\overline{\mathrm{e}}$ of a possible aetiological significance of these layers in the formation of atheroma. As atheroma increase 8 in number and size of lesion, so does the intimats 
picture become obscured; only in the early or less severe lesions are the internal lamina and other intimal layers seen to be intact below the lesion as it is pressed into the wall. Thus, no clear picture of an intimal pattern emerges in relation to hypertension.

Elastin in the media may be almost absent in a muscular artery. Fine and irregularly arranged fibres are not uncommon; these do not resemble the thick fibres of the adventitia. Where an artery, such as the external iliac artery, has not yet achieved the transition to the muscular type, the media possesses an intermediate appearance. This is a recognizable internal elastic lamina, and a network of elastin through the media becoming concentrated towards the outer part of the media further from the aorta and finally appearing as an external elastic lamina; further still it is seen as part of the adventitia. Some arteries contain irregular patches of elastin fibres in the media, for which no cause is seen; sometimes following a clear path from the adventitia through the outer part of the media and returning to the adventitia it may be that these channels represent the adventitia of vasa vasorum, but no evidence in support of this hypothesis has been found.

The adventitial elastin is a series of thick fibres running generally longitudinally, which sometimes appear as bundles of smaller fibres in transverse section; the appearance is of a network of elastin near the media, in which little collagen is seen, and a looser, less compact, elastin and collagen tissue further out.

Normal percentages of elastin in the media and adventitia were assessed visually, and appeared constant at different ages for any one site (Table II).

\section{TABLE II}

NORMAL PERCENTAGES OF ELASTIN IN MEDIA AND ADVENTITIA AT DIFFERENT AGES

\begin{tabular}{lcc} 
& Media & Adventitia \\
\hline Posterior communicating artery & 0 & 0 \\
Vertebral artery & 0 & 0 \\
Carotid artery & $30-40$ & $5-10$ \\
Renal arteries $\quad\{$ Peripheral & $0-5$ & $20-30$ \\
Femoral artery & 20 & 5 \\
Popliteal artery & $1-5$ & $10-30$ \\
Anterior tibial artery & $1-5$ & $20-30$ \\
Digital arteries & $1-5$ & $20-30$ \\
Brachial artery & 1 & $5-10$ \\
Radial artery & $1-5$ & $10-30$ \\
& $1-5$ & $5-20$
\end{tabular}

Certain exceptions were noted in excess of these percentages; media and adventitia were both affected, and usually several arteries from the same case were found to be similarly affected. The posterior communicating artery of a 47-year-old hypertensive male contained $5 \%$ and 10 to $20 \%$, and the percentage in

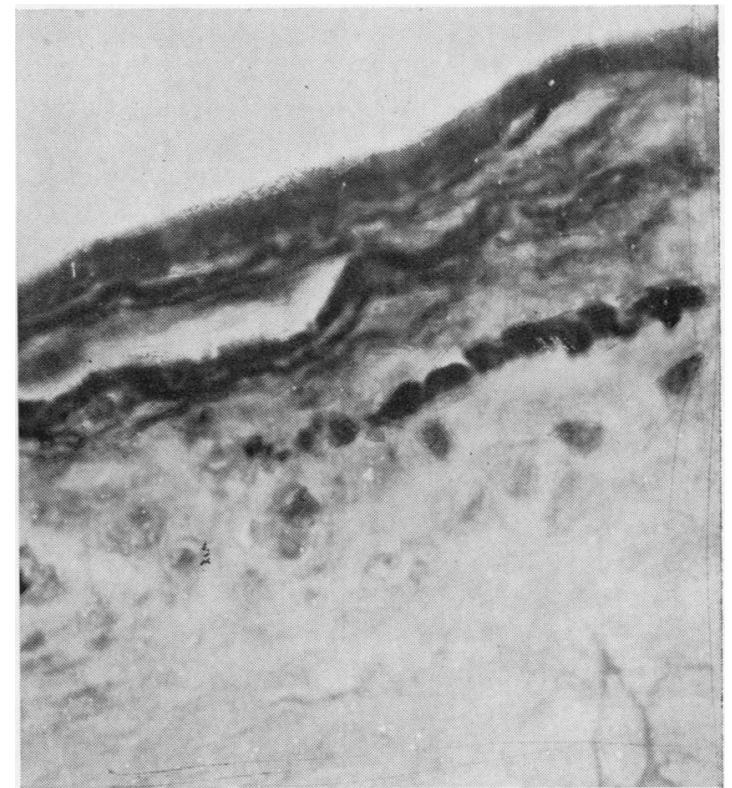

FIG. 26. Remnants of the internal elastic lamina and the intima in the same artery as in Fig. 25. Verhoeff $\times 640$.

the brachial, anterior tibial, and plantar digital arteries were each increased. All cases in which three or more arteries were similarly affected were hypertensive, several cases with one or two affected were not hypertensive, and one hypertensive, with a left ventricular wall $2 \cdot 2 \mathrm{~cm}$. thick, was not affected.

A peculiar feature of the adventitial elastin in some cases is the helical appearance shown in Figure 25. This comes from a moderate hypertensive of 70 years, but it can be found in younger cases, including children. There is no relationship to hypertension. Some of the sections show a somewhat similar appearance in the elastic lamina (Fig. 26) but the majority do not. The helices all stain as elastin, the main difference being in the paleness of some compared with the internal lamina elastin.

The focal nature of the calcification of the internal elastic lamina itself suggests that the lamina may undergo focal surface changes: this is also true of the lining layer which may take up Sudan IV focally in some arteries. Where fibrin stains are used, it is not uncommon to find foci on the internal lamina, and occasionally on the lining layer, which stains similarly to fibrin.

\section{DISCUSSION}

Hallenberger (1906), Aschoff (1905), and Thayer and Fabyan (1907) all examined radial and other arteries and were in general agreement that the appearance 
of an intima, and its subsequent thickening, came about by cells growing in from the media. These cells also caused separation of part of the internal elastic lamina forming a new intimal layer. They believe that this thickening was purposive, in order to strengthen the artery wall in response to rising blood pressure, and neglect the problems of growth but for mentioning that the longitudinal elastin fibres seen in the intima might slide apart during the extension of the artery. The variety of intimal proliferation and changes involving the internal elastic lamina, which are seen in this present series, is suggestive of a complex process, the main outcome being growth in length, breadth, and depth. The nature of the internal elastic lamina must be considered and whether it may be said to grow or to be added to in any way. Hallenberger saw its swollen and beaded appearance as a prelude to splitting of the lamina; but this appearance might equally be caused by deposit on the lamina, either from the plasma or from the endothelial cells. The primary interest of the pathologists at the beginning of this century was in the aetiology of arteriosclerosis and it may well be that physiological appearances in infancy and childhood were seen in this light alone.

Henle (1855-71) first described the internal elastic lamina as a fenestrated membrane; later anatomists described it as plexiform, with thick fibres and oval fenestrations in the long axis of the artery. For a summary of the early work on this subject, Dees (1923) should be consulted. She examined human and ox elastica, concluding that it consisted of a closemeshed feltwork of fine elastin fibres closely woven into a continuous sheet containing many openings, which were usually oval, with the long axis along the artery, some being crossed by fine fibres, giving a window-like appearance. In addition, there was an open-meshed network of coarser fibres, adherent to the luminal surface of the fine feltwork: openings in the two layers did not always coincide. In the present study, small perforations have been seen where the angle at which the section was cut allowed a surface view of the lesion.

Detailed examination of children's arteries has shown that when gaps appear in the internal elastic lamina they tend to be larger and appear more early in longitudinal section, which is compatible with stretching of a static lamina in a growing vessel. Thus the progressive increase in size and number of gaps suggests that no new elastica is laid down, the 'slack' of early infancy being taken up before perforations appear. Intimal elastin, possibly originating as a compressed lining layer, may make good the defects of the original elastica but it does not join it. It is possible that the new layers are produced by endothelial cells; none but a few muscle cells are otherwise present. Bory (1910) considered that the $\frac{\text { 은 }}{.}$ internal elastic lamina itself and the subsequent $\overrightarrow{\vec{F}}$ layers of elastin in the intima were laid down from the plasma.

In the present series, the musculo-elastic cushion $\frac{\bar{\sigma}}{\bar{c}}$ is a notable feature of the growth period. First $\frac{\vec{\sigma}}{\vec{\sigma}}$ described by Dock (1946) in the coronary arteries, $\stackrel{\square}{2}$ and ascribed by later authors (Levene, 1956; $\%$ Moon, 1957) an aetiological role in arteriosclerosis, $\vec{\circ}$ musculo-elastic cushions have been described in other foetal and infantile peripheral arteries by $\vec{\omega}$ Robertson (1960), who noted the higher incidence? in the lower limb, also noted in this study. He con-? sidered that these cushions represented a physio- $\vec{\sigma}$ logical response to stress by thickening the media. The findings in the present study are mainly in accord 0 with Robertson's statement that cushions occur $\odot$

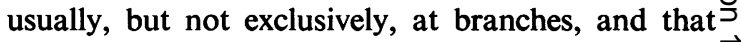
lipoid is not normally found in them. No suggestion $\vec{z}$ that these cushions might be the growing points of the vascular tree appears to have been made, and yet $\stackrel{\Phi}{3}$ it seems that some means by which the arteries of the leg increase in length by at least $300 \%$ must exist. Little increase in length is called for in the intra- $\vec{e}$ cranial arteries: if the musculo-elastic cushion is ac growing point, then its absence from these arteries $\square$ and commonness in the arteries of the leg would be explained.

Similar appearances have been described aso pathological features by DeMuth and Landing (1955) and by Dawson and Nabarro (1953) in cases of idiopathic cardiomegaly and hypertension respec-음 tively. In the present study, however, almost all the infants and children showed such cushions, and only? one presented the findings of hypertension; several children were in good health and died in accidents.

The preponderance of cushions at branches mayo be due to the need to increase the length of the vesseland to buttress such a junction. The popliteal arteryô is subject to marked external stresses, and is the site where very large longitudinal muscle bundles mayo always be found, and there seems little doubt that the bundles arise from the musculo-elastic cushions. The course of development of the cushion is not always equally clear, however. It seems possible that ${ }^{\circ}$ the cushion may be responsible for irregularities of 0 a focal nature, such as the varying amounts of elastin in the intima, which are a characteristic of arteryo walls. Even the relation of the network of elastino and muscle in the cushion to the internal elastic lamina seems to vary.

The varied and focal nature of the histology of the artery wall during the growth period has probablyo contributed to the widely held view that the roots of

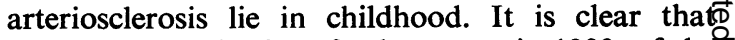
Aschoff held this view, for he wrote, in 1933, of the 
possibility of reversing them. At the same time he suggested that the ground or cement substance was of primary importance, thus reviving Thoma's (1883) view that medial nutrition became increasingly poor with age, leading to loss of elasticity and weakening, with compensatory intimal overgrowth, which in turn resulted in inadequate nutrition of this layer, leading to oedema and degeneration. This distinction between medial calcification and atheroma had not been made at the time and it is an interesting finding today that not only does medial calcification not occur without an accumulation of medial ground substance but that all arteries in which atheroma is seen show the same accumulation. It is clear from the few cases of organizing thrombi described in this series that even the femoral artery in a young woman of 18 , in which a thrombus was found, shows this change in the media.

The acceptance of Duguid's (1946) thrombogenic theory of atheroma does not lessen the need to understand the nature and functions of the ground substance in the arterial wall, although the deposit may be on a wall not histologically abnormal for the age and site. The generalized nature of the accumulation of the ground substance in an arterial media and intima does not exclude the possibility of a causal relationship with a lesion as focal as atheroma. Clearly the thrombogenic theory implies changes in the blood, resulting in a deposit on a part of the artery wall. That the generalized accumulation of ground substance is seen where the thrombus is not deposited, as well as where it is, does not justify neglecting the ground substance altogether. One or more factors must be active locally in order to initiate thrombosis. Recently, Hall and Wilkinson (1963) have suggested that an elastase, normally inactive in the blood stream, may act on a lipopolysaccharide-rich region of the aortic elastica, if revealed by damage to the endothelium, and this complex would present a proteolytic enzyme system capable of initiating localized thrombosis. They have demonstrated that free elastase reduces the clotting time of platelet-free recalcified plasma. Gore and Larkey (1960) have reported that the only elastase isolated from mammalian tissue outside the pancreas was from a crude polysaccharide fraction from the aorta, which implies that some adsorption occurs naturally. Protective substances, of a lipoprotein or mucopolysaccharide nature, which prevent elastolysis, have also been described (Saxl, 1957; $\mathrm{Yu}$ and Blumenthal, 1958) and have been isolated from the aortas of young subjects.

The ground substance of the arterial wall is generally held to be a water-holding mucopolysaccharide, capable of effecting changes between intravascular fluids and parenchymal cytoplasm, and probably acting as a lubricant. Its permeability is altered by spreading factors and their inhibitors and by hormones (Duran Reynals, et al., 1950). It is known to be related to collagen formation and the growth of fibroblasts. Gersh and Catchpole (1949) have suggested that elastin and mucopolysaccharide may be inter-transformable by enzyme systems, though some chemists, e.g., Partridge and Davis, (1955), have denied that sufficient hexosamine is liberated on hydrolysis of elastin. Moon and Rinehart (1952), noting the appearance of mucopolysaccharide in a plaque, conclude that lipids are rendered insoluble by mucopolysaccharide, rather than secondary accumulation of mucopolysaccharide after deposition of cholesterol as Gore and Barr (1959) concluded, working with cholesterolized rabbits. Further evidence of the complex relationship of lipids and ground substance has been produced by Gillman and Naidoo (1957), who have shown that the mucopolysaccharide in the presence of calcium ions is capable of splitting post-prandial chylomicrons.

The formation of the ground substance in the vascular wall may differ in the intima and media. According to Moore and Schoenberg (1957), the inner part of the wall and capillary endothelium contain chondroitin sulphate, and the outer, hyaluronic acid. Curran (1957) has shown that in mice the endothelium of capillaries and other vessels takes up labelled sulphate, and must, therefore, be considered one source of ground substance. Other potential sources of ground substance are elastin breakdown (Taylor, 1953) and production, as in granulation tissue, from blood products and cells, probably fibroblasts (Boucek and Noble, 1955).

During the examination of the arteries described in this series, it is clear that the somewhat eosiniphilic ground substance of the child's intima differs in its affinity for stains from the more basophilic material seen in the media and intima of adult life, which usually exactly resembles the ground substance seen in an organizing thrombus. A fourth type is seen in the small intensely basophilic pools occasionally found adjacent to calcified internal elastic lamina. Further, it has been apparent that lipid appears in the intima already well stocked with ground substance. It therefore seems possible that the initial ground substance seen in intima comes from endothelium, providing nutrition for elastin or for production of new elastin, and differing from the more basophilic variety seen later, the appearance of which suggests a possible origin in the blood, because of the similarity to that of the thrombus. The small, highly basophilic pools might be due to elastin breakdown, as they are seen only in areas of elastin changed from the normal. It is not likely that the great accumulation of medial mucopoly- 
saccharide could come from medial elastin alone, as has been suggested by Taylor (1953) from aortic appearances. The bizarre appearances of medial muscle cells in severe accumulations of ground substance may be explicable by degeneration, regeneration, or both.

I wish to thank Professor K. R. Hill for his continuing interest and encouragement. Mr. Conolly, of the Institute of Laryngology, kindly took the photographs for Figures 14 and 16-19.

\section{REFERENCES}

Aschoff, A. (1905). S-B. Ges. ges. Naturw. Marburg, Nr. 8, 117. Aschoff, L. (1933). In Arteriosclerosis, edited by E. V. Cowdry, p. 1. Macmillan, New York.

Bory, L. (1910). Arch. Mal. Coeur, 3, 302.

Boucek, R. J., and Noble, N. L. (1955). Arch Path., 59., 553.

Curran, R. C. (1957). J. Path. Bact., 74, 347.

Dawson, I. M. P., and Nabarro, S. (1953). Ibid., 66, 493.

Dees, M. B. (1923). Anat. Rec., 26, 161.

DeMuth, G. R., and Landing, B. H. (1955). Amer. Heart J., 50, 643.

Dock, W. (1946). J. Amer. med. Ass., 131, 875.

Duguid, J. B. (1946). J. Path. Bact., 58, 207.
Duran Reynals, F. et al. (1950). Symposium on the Ground Substance of the Mesenchyme and Hyaluvonidase, Ann. N.Y: Acad. Sci., 52, 943.

Gersh, I., and Catchpole, H. R. (1949). Amer. J. Anat., 85, 457.

Gillman, T., and Naidoo, S. S. (1957). Nature (Lond.), 179, 904.

Gore, I., and Barr, R. (1959). Lab. Invest., 8, 395. and Larkey, B. J. (1960). J. Lab. clin. Med., 56, 839.

Hall, D. A., and Wilkinson, J. E. (1963). Nature (Lond.), 197, 454.

Hallenberger, O. (1906). Dtsch. Arch. klin. Med., 87, 62.

Hass, G. M. (1943). Arch. Path., 35, 29.

, Trueheart, R. E., Taylor, C. B., and Stumpe, M. (1958). Amer J. Path., 34, 395.

Henle, J. (1855-71). Handbuch der systematischen Anatomie des $\overrightarrow{0}$ Menschen. Vieweg, Brunswick.

Levene, C. I. (1956). J. Path. Bact., 72, 79, 83.

Matusewitz, J. (1902). Beitr. path. Anat., 31, 217.

Mönckeberg, J. G. (1903). Virchows Arch. path. Anat., 171, 141.

Moon, H. D. (1957). Circulation, 16, 263.

-, and Rinehart, J. F. (1952). Ibid., 6, 481.

Moore, R. D., and Schoenberg, M. D. (1957). Arch. Path., 64, $39 . \quad \vec{\sigma}$

Moran, J. J., and Becker, S. M. (1959). Amer. J. clin. Path., 31, 517 -

Partridge, S. M., and Davis, H. F. (1955). Biochem. J., 61, 21.

Robertson, J. H. (1960). J. clin. Path., 13, 133, 199.

Saxl, H. (1957). Proceedings 4th Conference international Association of Gerontology, Merano, vol. 2, p. 67.

Taylor, H. E. (1953). Amer. J. Path., 29, 871.

Thayer, W. S., and Fabyan, M. (1907). Amer. J. med. Sci., 134, 811.

Thoma, R. (1883). Virchows Arch. path. Anat., 93, 443.

Yu, S. Y., and Blumenthal, H. T. (1958). J. Geront., 13, 366. 